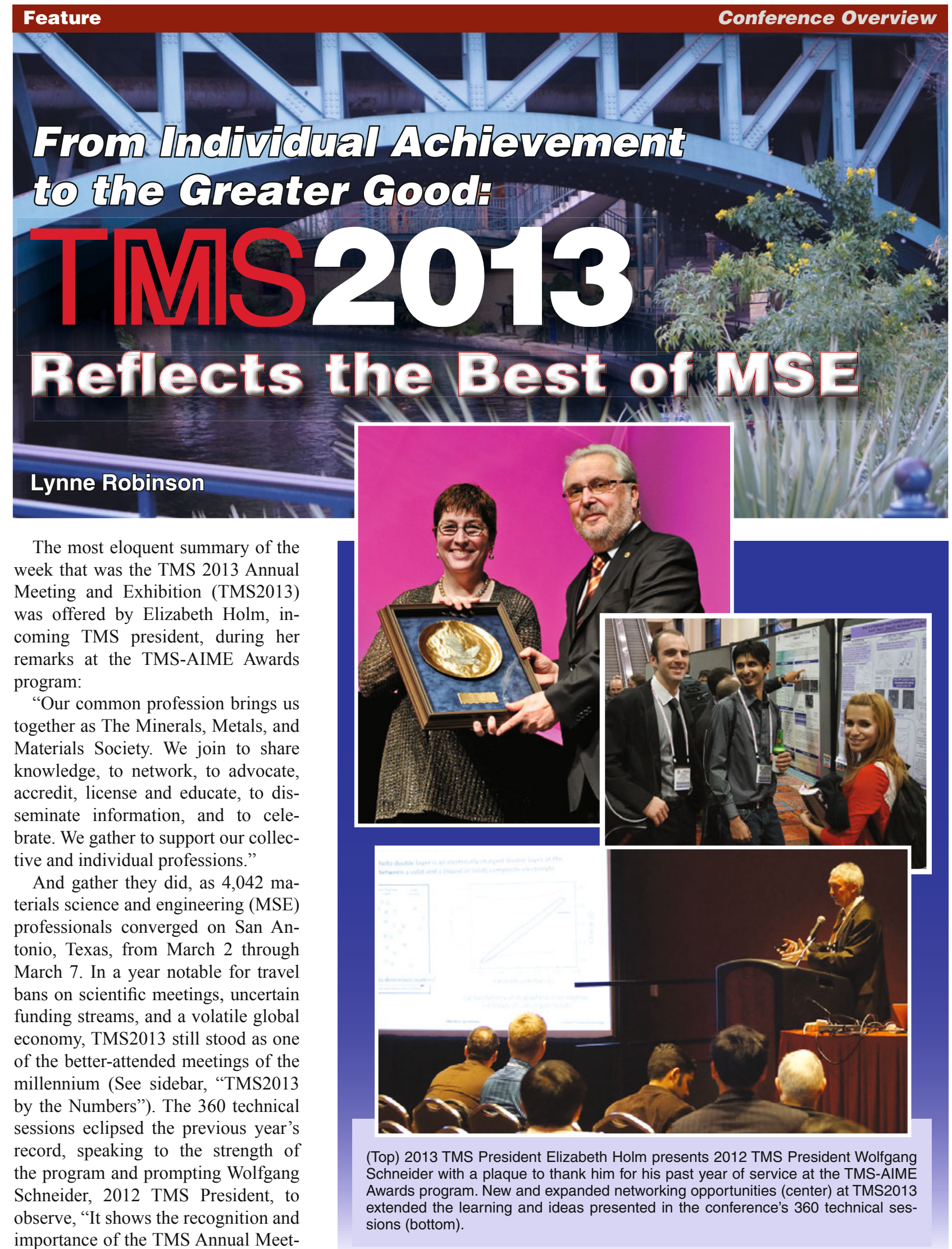




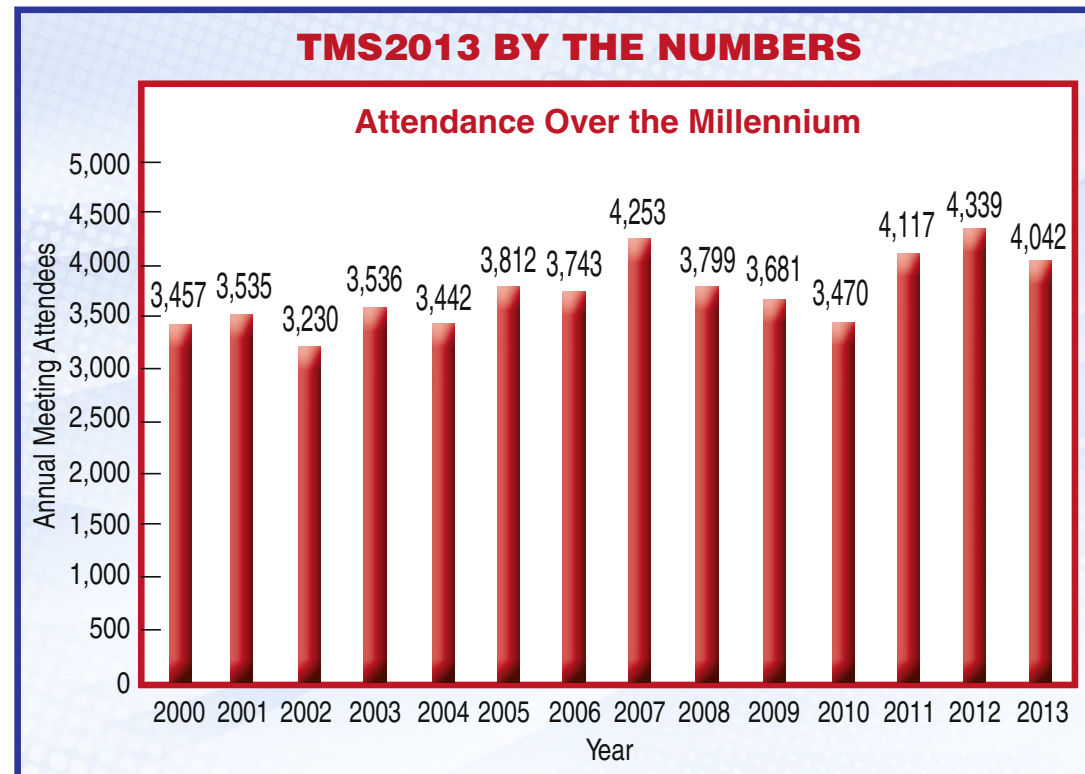

Figure A. TMS2013 was one of the most well-attended conferences of the last century.

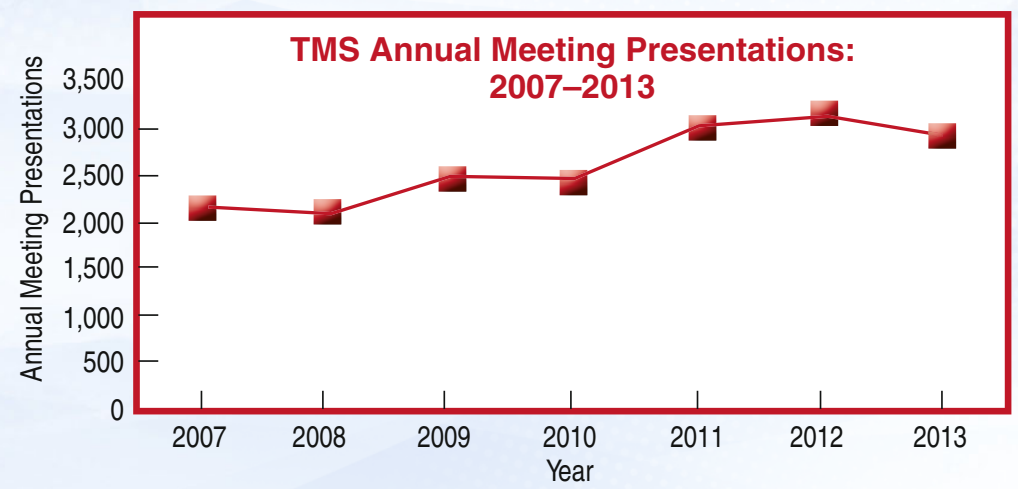

Figure $\mathrm{C}$. While economic factors contributed to a slight dip in presentations made from last year's all-time high, TMS2013 still set a society record of total abstracts submitted for consideration at 4005 .

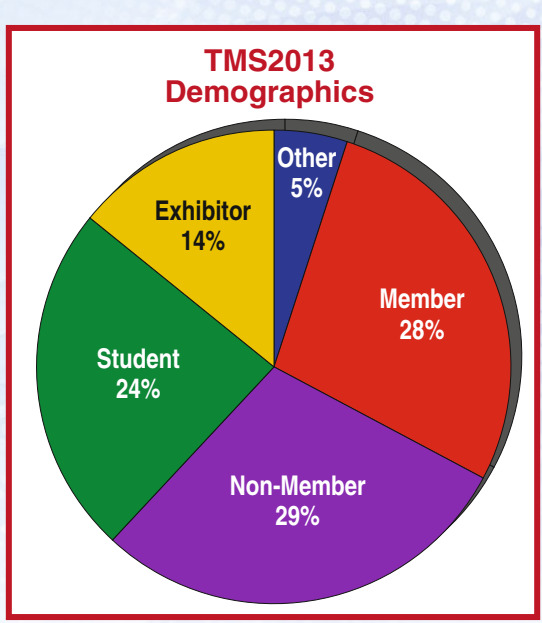

Figure B. A closer look at who attended this year's conference.

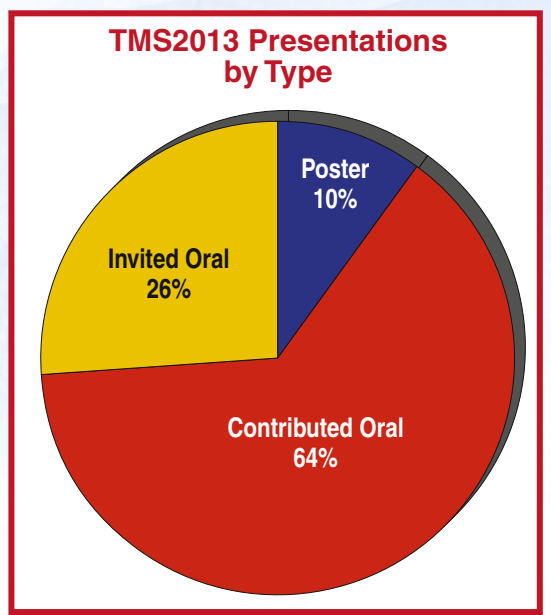

Figure D. A broad overview of the types of presentations made at TMS2013. world." At TMS2013, that "materials world" encompassed a vast geography-nearly half of the attendees hailed from outside the United States, and in total, represented 61 nations and every inhabited continent.

Beyond the session and meeting rooms, TMS2013 attendees conducted important work over quick meals and informal gatherings, with several new and enhanced opportunities for these experiences introduced at this year's conference. Between events, the halls and sunlit common places of the Henry B. Gonzalez Convention Center hummed with conversation and activity. Holm noted that this high level of engagement was a critical factor in the current success and ongoing value of TMS. "The true core of TMS is its members. I am lucky to inherit TMS at a time when this core is exceptionally strong, supporting a great balance of activities in every area impacting our profession," she said. "My goal for my presidency is to refocus on these sustaining members and activities, and

\section{TMS2013 AWARDS AND RECOGNITION}

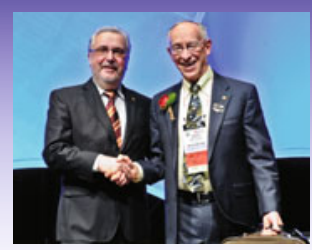

Past President Garry Warren $(R)$ is recognized for his service by 2012 President Wolfgang Schneider (L).

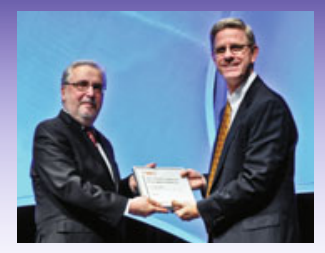

Kevin Hemker (R), retiring TMS Board member, is thanked by Schneider.

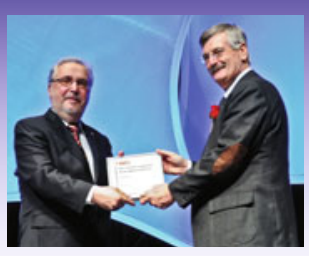

Schneider thanks James Sears (R), retiring TMS Board member, for his service.

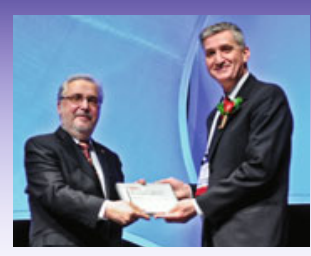

John Hryn (R), retiring TMS Board member, receives recognition for his service from Schneider.

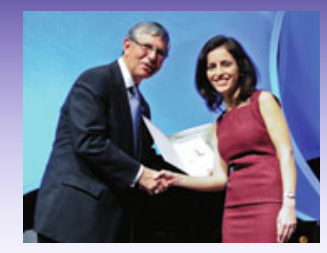

George Luxbacher (L), AIME President, congratulates $\mathrm{Nia}$ Abdolrahim (R), AlME Henry DeWitt Smith Scholarship winner. 
to ensure that the professional society that has served them so well since 1871 remains their destination of choice for the next 142 years."

Within the context of that larger goal, Holm said that she will emphasize development of programs and resources to support young and midcareer professionals. "Our student members enjoy a formal and informal network of educational and mentoring resources. Our senior members enjoy the confidence that comes from experience," she said. "In contrast, the mid-career professional often faces new challenges - such as changing job roles and responsibilities - without either of these benefits."

Strengthening TMS's geographic and demographic diversity is also a priority for Holm, acknowledging that even though TMS cannot solve root societal issues, "we can make progress here at home."

"We can uncover the issues that challenge our diverse members both inside TMS and in the workplace," Holm said. "And, we can offer programs and services that help sustain this diverse membership, especially through the vulnerable graduate student and mid-career years."

The groundwork for these and many other initiatives was laid throughout the busy days of TMS2013, with continued developments slated to unfold in the coming year. The following pages offer a glimpse of some of these activities, while trying to capture the aspects of the TMS2013 experience that made it more than "just a meeting" for many of the attendees. As Holm observed, "At their very best, professional societies are the catalysts for a million events - small things that change the world."
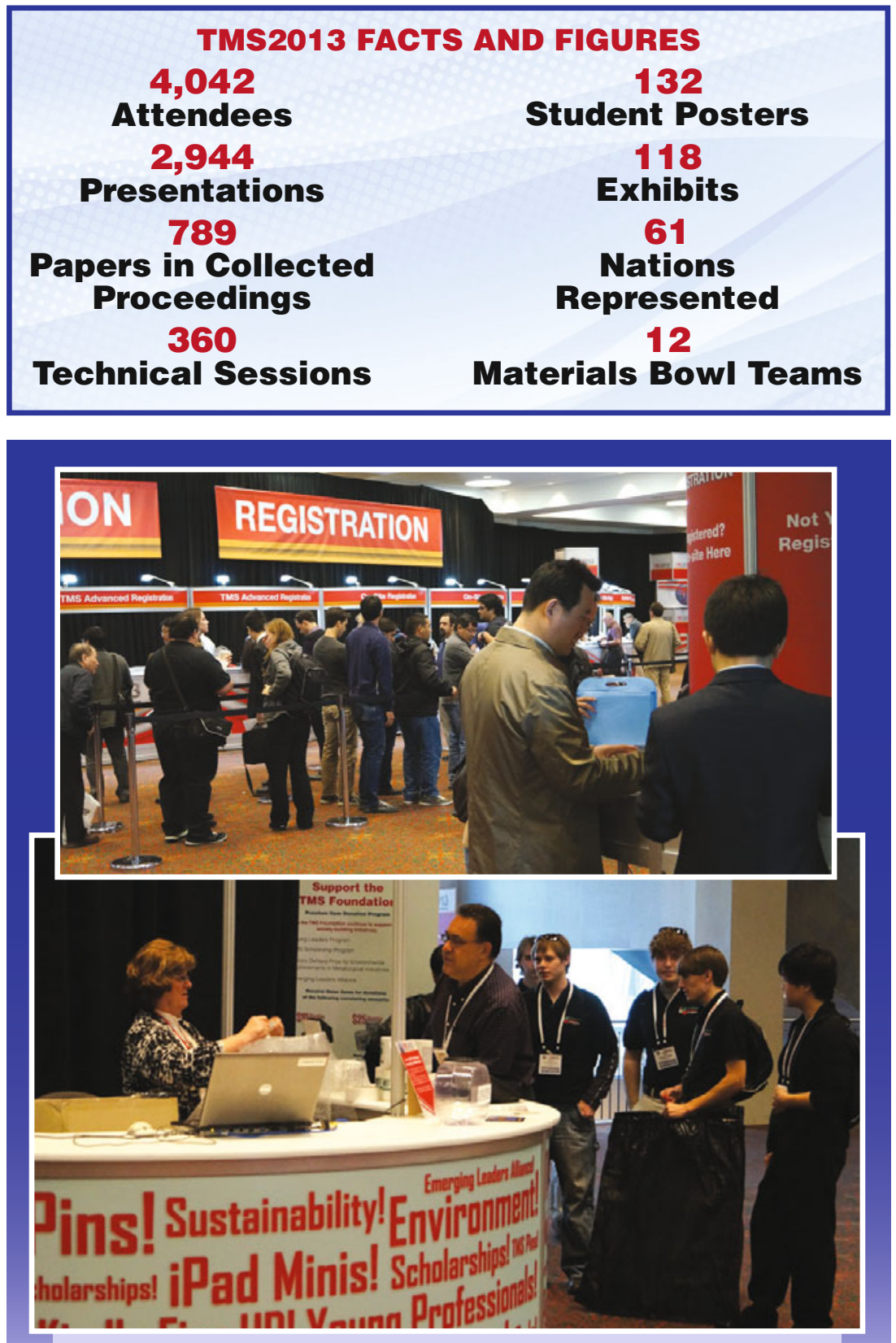

(Top) With new participation options offered this year, the TMS2013 registration area was busy throughout the conference. (Bottom) The TMS Foundation booth highlighted the important role that the Foundation plays in advancing the society's mission.

\section{TMS2013 AWARDS AND RECOGNITION}

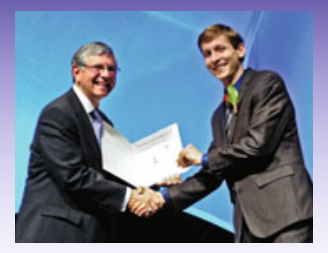

Dmitri Nassyrov (R) formally receives the AIME Henry DeWitt Smith Scholarship from Luxbacher.

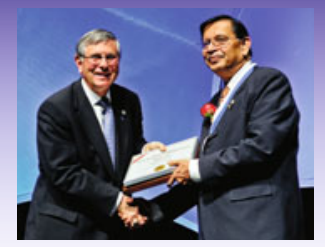

Luxbacher confers AIME Honorary Membership on Bhakta Rath (R).

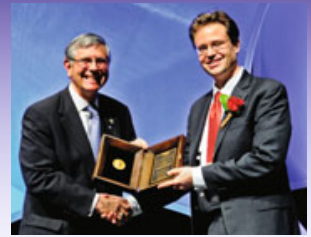

Markus Buehler (R) receives the AIME Robert Lansing Hardy Award from Luxbacher.

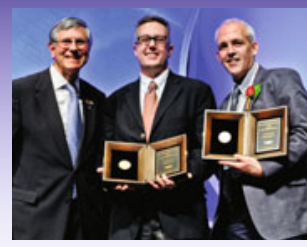

Luxbacher with Paul Krajewski (R) and EricTaleff (C), the AIME Champion H. Mathewson Award winners.

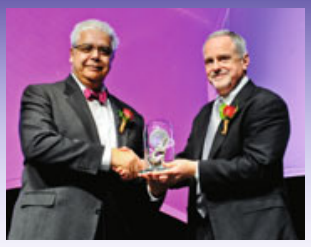

Jonathan Dantzig $(\mathrm{R})$ receives the J. Keith Brimacombe Prize from Hani Henein (L). 


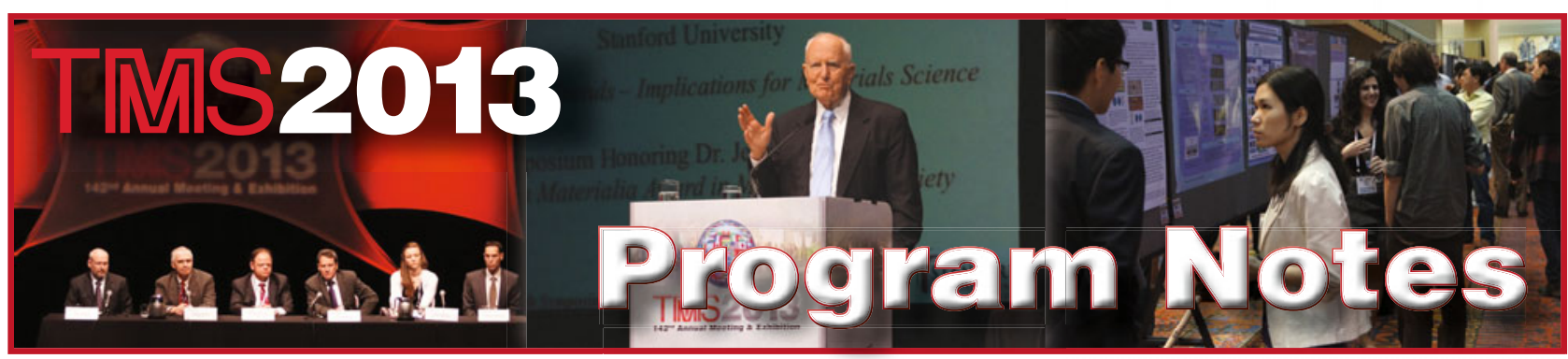

TMS2013 offered one of the strongest technical programs in the organization's history, with 2,944 oral and poster presentations made within 360 sessions. Highlighting this year's agenda was a selection of special plenary and keynote sessions bringing diverse attendee groups together to explore topics of common interest.

While impossible to document every idea posed and research finding recounted at the conference, the ability to capture and share a few program highlights was significantly enhanced this year through the efforts of two TMS graduate student members, Graham Sanborn and Alex Leary. Through funding provided by the International Center for Materials Research (ICMR) Apprentice Science Reporter Program, University of California, Santa Barbara, Sanborn and Leary served as onsite reporters, offering fresh perspectives to TMS2013 attendees on a variety of sessions and events. Their articles and summaries were published in the daily TMS2013 e-newsletter, with excerpts presented in this section of JOM's conference overview. To read the full articles, go to the TMS2013 website at http $: / / w w w . t m s . o r g / t m s 2013$. For insights on the graduate student reporter program, read the sidebar article, "Meet the TMS2013 Apprentice Science Reporters."

\section{TOP 20 TMS2013 SYMPOSIA}

\section{Symposia}

Papers

Phase Transformation and Microstructural Evolution

Presented

Bulk Metallic Glasses X

120

106

Modeling and Experimental Validation of Multiscale Mechanical

Behavior from Atomic Scale to Macro Scale

Magnesium Technology 2013

Microstructural Processes in Irradiated Materials

91

Biological Materials Science Symposium

Neutron and X-Ray Studies of Advanced Materials VI: Centennial and Beyond

Characterization of Minerals, Metals and Materials 2013

2013 Functional Nanomaterials: Synthesis, Properties and Applications

Nanostructured Materials for Lithium Ion Batteries and for

Supercapacitors

$\mathrm{Pb}$-free Solders and Emerging Interconnect and Packaging

Technologies

Physical and Mechanical Metallurgy of Shape Memory Alloys

4th International Symposium on High-Temperature Metallurgical

Processing

Friction Stir Welding and Processing VII 62

Aluminum Reduction Technology $\quad 61$

Aluminum Alloys: Fabrication, Characterization and Applications $\quad \mathbf{5 9}$

Materials and Fuels for the Current and Advanced Nuclear Reactors II $\quad 58$

Deformation, Damage, and Fracture of Light Metals and Alloys $\quad 57$

Advanced Materials and Reservoir Engineering for Extreme

Oil \& Gas Environments

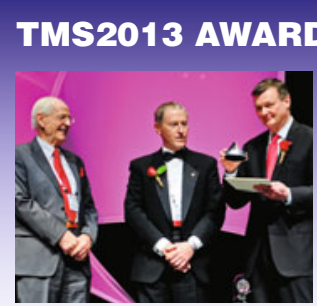

Jeffrey Wadsworth (R) accepts his Acta Materialia Materials and Society Award from George (Rusty) Gray, III (C) and Thaddeus B. Massalski (L).

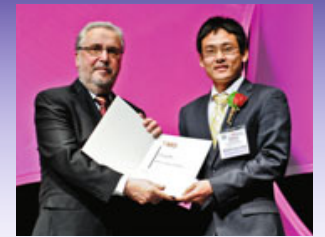

Chih-Pin Chuang $(\mathrm{R})$ receives the 2nd place Graduate Student Best Paper Contest award from Schneider.

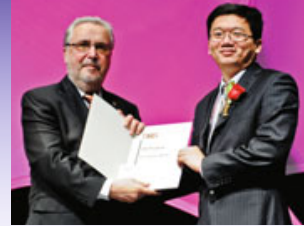

Cheng Sun (R), 1st place Graduate Student Best Paper Contest winner, accepts his award from Schneider.

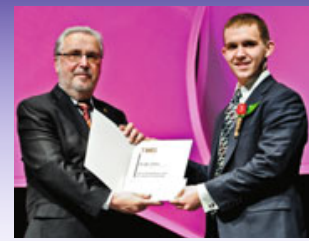

Schneider awards Bradley Potter $(R)$ with the TMS J. Keith Brimacombe Presidential Scholarship.

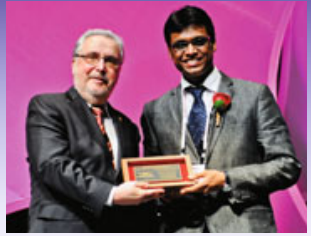

Sumit Goenka $(R)$ receives the TMS Foundation Shri Ram Arora Award from Schneider. 


\section{MEET THE TMS2013 APPRENTICE SCIENCE REPORTERS}

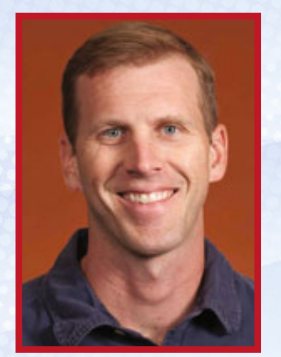

Alex M. Leary

Materials Science Graduate Student Carnegie Mellon University

Education:

M.S. in Materials Science,

Carnegie Mellon University (CMU)

M.S. in Bioengineering,

University of Pittsburgh

B.S. in Mechanical Engineering,

University of Virginia

Accomplishments:

Leary holds the rank of lieutenant in the United States Navy. He served as an action officer with the NATO training mission in Kabul, Afghanistan, and as an assistant professor of Naval Science at the CMU Navy ROTC. From 2004-2007, he was designated a mission and aircraft commander and P-3C Orion Pilot for Patrol Squadron One based on Whidbey Island, Washington.

Looking Back at TMS2013:

"When scheduling your conference itinerary, have you ever wished that you could be in more than one place at once? TMS publishes a daily web-based conference newsletter that is a great way to keep up with any missed sessions. This year, TMS offered conference reporter positions to students and I jumped at the chance. I met the TMS staff during a pre-conference meeting where we discussed event coverage and received some helpful hints."

"My coverage schedule included several sessions outside my core research area. This initially concerned me, as my student reporter function was to contribute a technical understanding to the coverage. Would I be able to accurately capture the relevant topics of a field outside my core research area? As I attended the sessions and assumed the reporter role, two things became apparent. The first was that good speakers not only make these important points abundantly clear, but also provide background and explanation to a non-specialist audience. TMS2013 had a wealth of great speakers and I particularly enjoyed the question and answer sessions following the talks. The second aspect was a reflection on my own work. Would an outsider walk away from my talk with a clear understanding? Listening for direct quotes was a new experience for me that opened my eyes to how I communicate my work and read news coverage in general."

"As researchers, we need to effectively communicate our work to a wide audience. As students, conferences may be the first chance to present work and interact with the wider community outside our respective universities. Be sure to look out next year for the call for student reporters and take advantage of this fantastic opportunity."

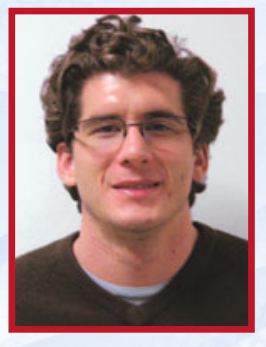

\section{Graham P. Sanborn}

Ph.D. Candidate, Materials Science and Engineering Georgia Institute of Technology

Education:

M.S. in Materials Science, Georgia Institute of Technology (Georgia Tech) B.S. in Chemistry, Minor in Mathematics, Spring Hill College

\section{Accomplishments:}

Sanborn currently holds a fellowship with Technological Innovation: Generating Economic Results (TI:GER), an interdisciplinary opportunity offered in collaboration with the Georgia Tech MBA and Emory Law programs. His Ph.D. thesis research focuses on carbon nanomaterial and silicon micro-fabrication technologies to create an electron source on a silicon chip.

Looking Back at TMS2013:

"My experience at TMS2013 was valuable and rewarding. The different writing style was a refreshing change from the traditional scientific writing I normally do. The articles still have a technical focus, but they also need to be succinct and informative to a broad scientific audience. In addition, they had to be written quickly for the daily deadline - a real challenge for some late afternoon sessions. It isn't often in graduate school that you have to write something on a topic you learned about earlier in the day. I believe my experience with this writing style will prove practical and useful for my career."

"The reporter position also provided a unique insight during the conference. The typical benefits from attending a conference, such as networking and education, were enhanced by this position. Since I was covering specific events, I had the opportunity to talk with and meet professionals I normally wouldn't encounter. In addition, most participants had heard about the graduate student reporter program, so meeting people at networking and social events was much easier. Finally, I was able to attend sessions I normally wouldn't attend as a student, such as symposia luncheons, which proved to be highly informative."

"Attending TMS2013 as a graduate student science reporter was a great educational opportunity. The writing experience, scientific education, and networking opportunities were an outstanding enhancement of the typical conference experience. I am very grateful for this and would like to thank the International Center for Materials Research (ICMR) Apprentice Science Reporter Program for this opportunity."

\section{TMS2013 AWARDS AND RECOGNITION}

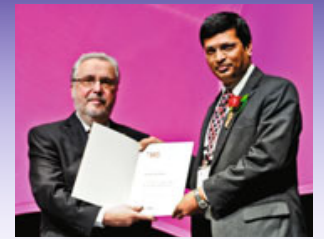

Schneider recognizes Sandip Harimkar (R) as the $2013 \mathrm{JIM} /$ TMS Young Leader International Scholar.

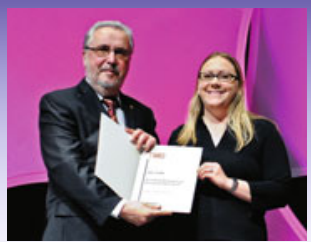

Amy Clarke $(\mathrm{R})$ was recognized by Schneider as the first FEMS/ TMS Young Leader International Scholar.

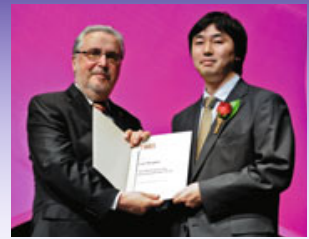

Schneider congratulates Yoj Miyajima (R) as the JIM International Scholar.

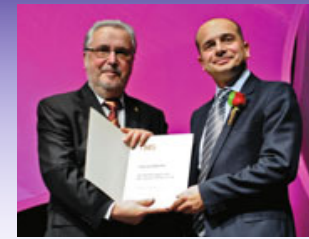

Vincenzo Palermo $(R)$ is recognized by Schneider as the FEMS International Scholar.

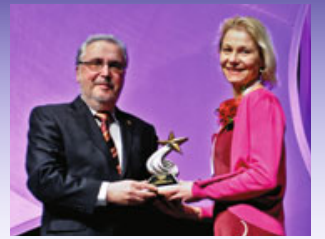

Julia Greer (R) accepts the Early Career Faculty Fellow Award from Schneider. 


\section{REWAS 2013: Collaborations and Sustainability \\ By Alex Leary}

Organizers planned REWAS 2013 to be a platform for stakeholders from different fields to interact and discuss the implementation of sustainable products and processes. Helga Vanthournout from McKinsey \& Co. summed up a recurring theme during the opening plenary, stating "more collaboration is needed since scale is required to create value across the supply chain."

Leaders in several business sectors described the challenges facing their respective industries. Todd DiNoia, Technical Director, Habitat R\&D, Saint-Gobain, framed the issue in the building industry by contrasting the significant efficiency gains in the transportation sector over the past 30 years to the relatively flat performance from building technologies. DiNoia went on to describe investments by Saint-Gobain into several technology areas, including electronically tintable glass, solid oxide fuel cells, IR reflective roof shingles, and VOC scavenging wall boards.

The needs in the building industry,

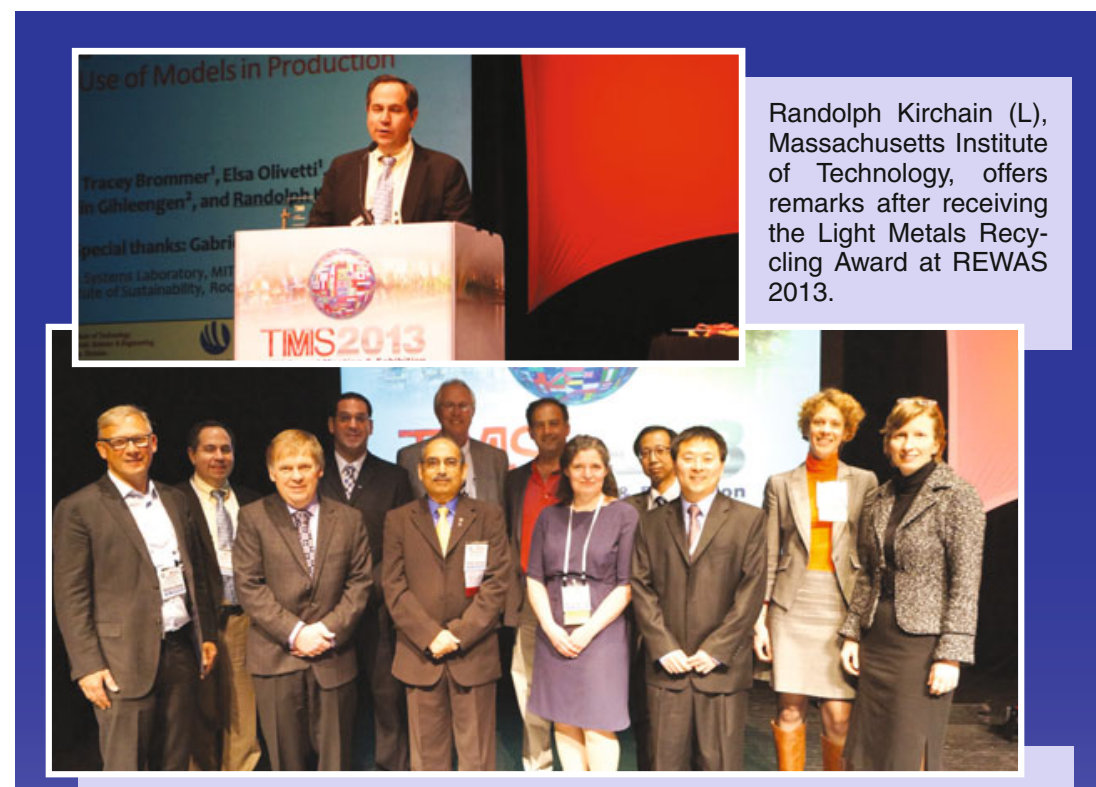

Pictured above are members of the REWAS 2013 organizing and international scientific committees, as well as the REWAS 2013 opening plenary speakers. Back row (L-R): Randolph Kirchain, Massachusetts Institute of Technology; Todd DiNoia, Saint-Gobain High Performance Materials; William A. Bonkoski, GE Water \& Process Technologies; S. Julio Friedmann, Lawrence Livermore National Laboratory; Yongziang Yang, Delft University of Technology. Front row (L-R): Maurits Van Camp, Umicore Group; Bill Bader, International Electronics Manufacturing Initiative (iNEMI); Brajendra Mishra, Colorado School of Mines; Anne Kvithyld, SINTEF; Cong Wang, Saint-Gobain High Performance Materials; Christina Meskers, Umicore Group; Helga Vanthournout, McKinsey \& Company and the Ellen MacArthur Foundation.

where the typical product lifecycle is 50 years in the United States, was contrasted by the rapid market growth and short device life cycle found in the electronics industry. Bill Bader, Chief Executive Officer, International Electronics Manufacturing Initiative (iNEMI), discussed the roadmap that his organization generates. When asked how he organizes input from potential competitors, Bader replied, "The key to successful collaboration is to pick problems that are pre-competitive in nature and where intellectual property is not at risk. Solutions to environmental problems often fit this criteria and we have situations where four to six of the top companies in the electronics world are working together."

Bill Bonkoski from GE offered his perspective on water resources. Over the course of his career, the low price of water limited the incorporation of new technologies, but he noted that "the scarcity problems that we're seeing in the world have spurred growth in the use of technology in the water industry." He also reported that a new system, based on various levels of reuse, is being developed to accommodate needs in urban and rural areas.

Vanthournout further described the need to modify production and consumption systems. She called for more sophisticated business models that not only recycle, but also incorporate reuse and remanufacturing of materials that were previously considered waste.

Julio Friedmann, Lawrence Livermore National Laboratory, concluded the session by describing several key technologies that are speeding up the innovation cycle in materials design. These include modeling to screen potential materials and advanced manufacturing processes.

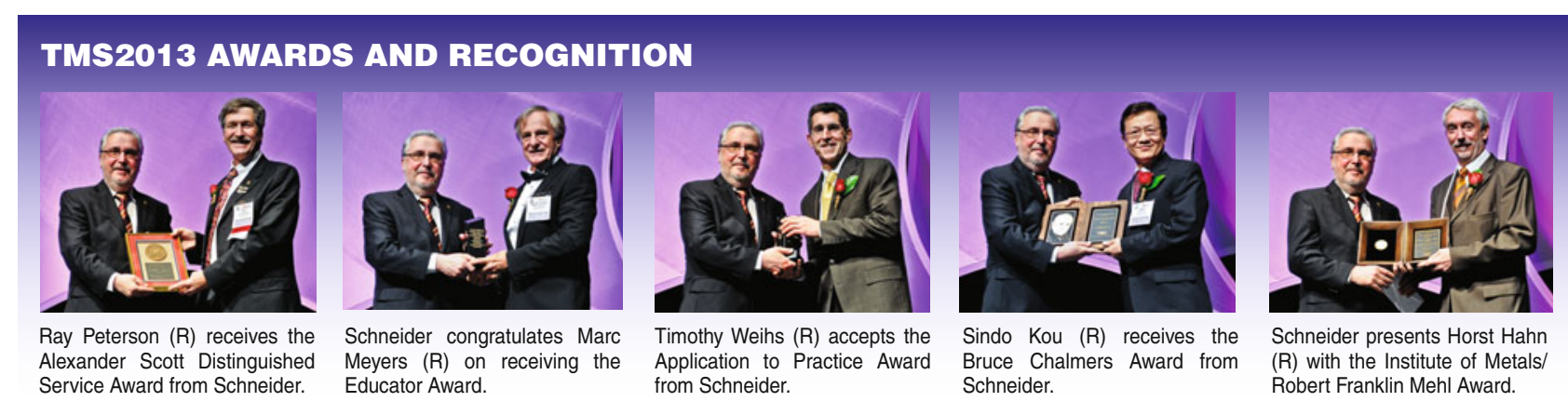




\section{Symposium Examines Magnesium Alloy \\ Development By Graham Sanborn}

Magnesium Technology 2013 kicked off with a special plenary that covered a range of topics, from magnesium grain refinement technology, to corrosion resistance testing, to phase transformations.

Karl Kainer, Helmholtz-Zentrum Geesthacht, opened the session with a review of magnesium alloys in the $21 \mathrm{st}$ century, detailing the process development of high-purity alloys.

An invited talk by David StJohn, University of Queensland, covered the history of grain refinement technology in cast magnesium alloys. This included StJohn's own work on the Interdependance Theory as a theoretical framework to understand the mechanism of grain refinement and the role of solutes.

Joy Forsmark, Ford Motor Company, gave an update on the United States Automotive Materials Partnership (USAMP) magnesium front end research and development project. Specifically, Forsmark reviewed results from the first phase, which set out to develop and test a magnesium "demonstration" structure.

Robert C. McCune, Robert C. McCune \& Associates LLC, built on Forsmark's presentation with a discussion on how the automotive industry could use better characterization methods, and presented results from the $\mathrm{AC}$ DC-AC and impedance spectroscopy testing methods.

Rainer Schmid-Fetzer, Clausthal University of Technology, presented on the thermodynamics of phase transformations in Mg-La-Ce-Nd alloys

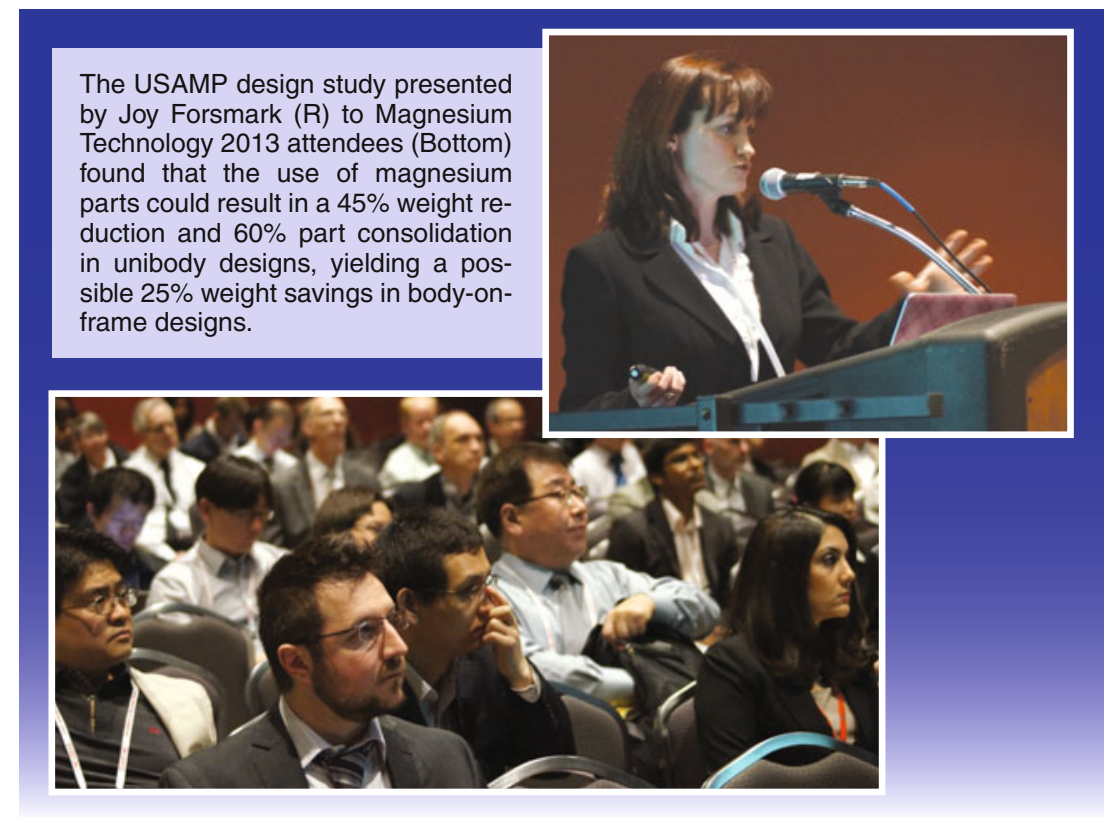

\section{DOWNLOAD THE TMS2013 CONFERENCE PROCEEDINGS BY SEPTEMBER 3}

TMS2013 introduced a new approach to distributing the published conference proceedings to meeting attendees. Instead of receiving a CD-ROM, TMS2013 attendees were provided with a web address to download the proceedings as an e-book bundle or single-paper PDF files. TMS2013 attendees have free access to the online proceedings until September 3 - standard member pricing will then go into effect at that time. For assistance with downloading the proceedings, please contact publications@tms.org.

The print proceedings are also available for purchase at the Wiley Online Library. TMS members are eligible for a 25 percent discount for these and other Wiley publications. To access the discount code, log in to the TMS Members Only home page and select "Publications" under "Member Reading Room" on the menu bar. The TMS2013 proceedings publications include:
- Light Metals 2013

- Magnesium Technology 2013

- EPD Congress 2013

- $4^{\text {th }}$ International Symposium on High-Temperature Metallurgical Processing

- Characterization of Minerals, Metals, and Materials 2013

for new material development in the industry. Yoshihito Kawamura, $\mathrm{Ku}$ mamoto University, concluded the
- Energy Technology 2013

- Friction Stir Welding and Processing VII

- Materials Processing Fundamentals

- Ni-Co 2013

- REWAS 2013

- TMS2013 Supplemental Proceedings plenary with a presentation on current developments of high strength and non-flammable magnesium alloys.

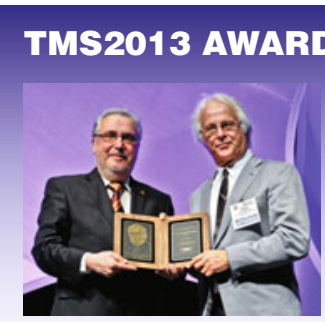

Alex Zunger (R) accepts the William Hume-Rothery Award from Schneider.

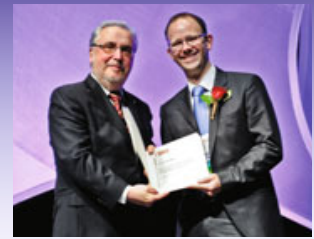

Schneider congratulates Leon Prentice (R) for winning the Vittorio de Nora Prize for Environmental Improvements in Metallurgical Industries.

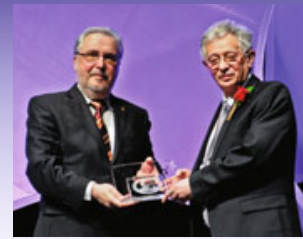

Leonid Bendersky $(R)$ receive the Cyril Stanley Smith Award from Schneider.

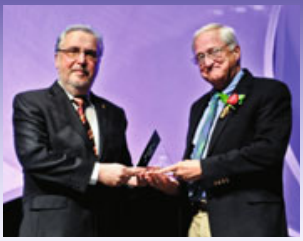

Schneider presents Gregory Olson (R) with the Morris Cohen Award.

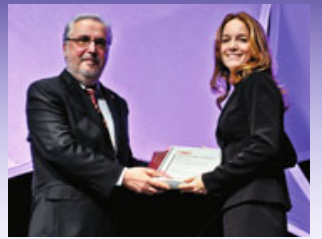

Schneider recognizes Ellen Cerreta $(R)$ as a 2013 Brimacombe Medalist. 


\section{Aluminum Keynote Session Covers the Spectrum of "Impurities in the Aluminum Supply Chain"}

Examining the impact of impurities across the entirety of the aluminum industry was the focus of the TMS2013 Aluminum Keynote Session. While each of the seven presenters focused on different issues, approaches, and technologies, a consistent theme underscored each of them, noted Barry
Sadler, program organizer and editor of this year's Light Metals, in his opening remarks: "There has already been a lot of work underway on impurity issues and it will only continue to grow."

Setting the stage for the subsequent discussions was Stephen Lindsay, Alcoa, in his talk, "Raw Material Impurities and the Challenge Ahead." As the demand on the existing resources for raw materials increases, raw material purity is likely to decline over

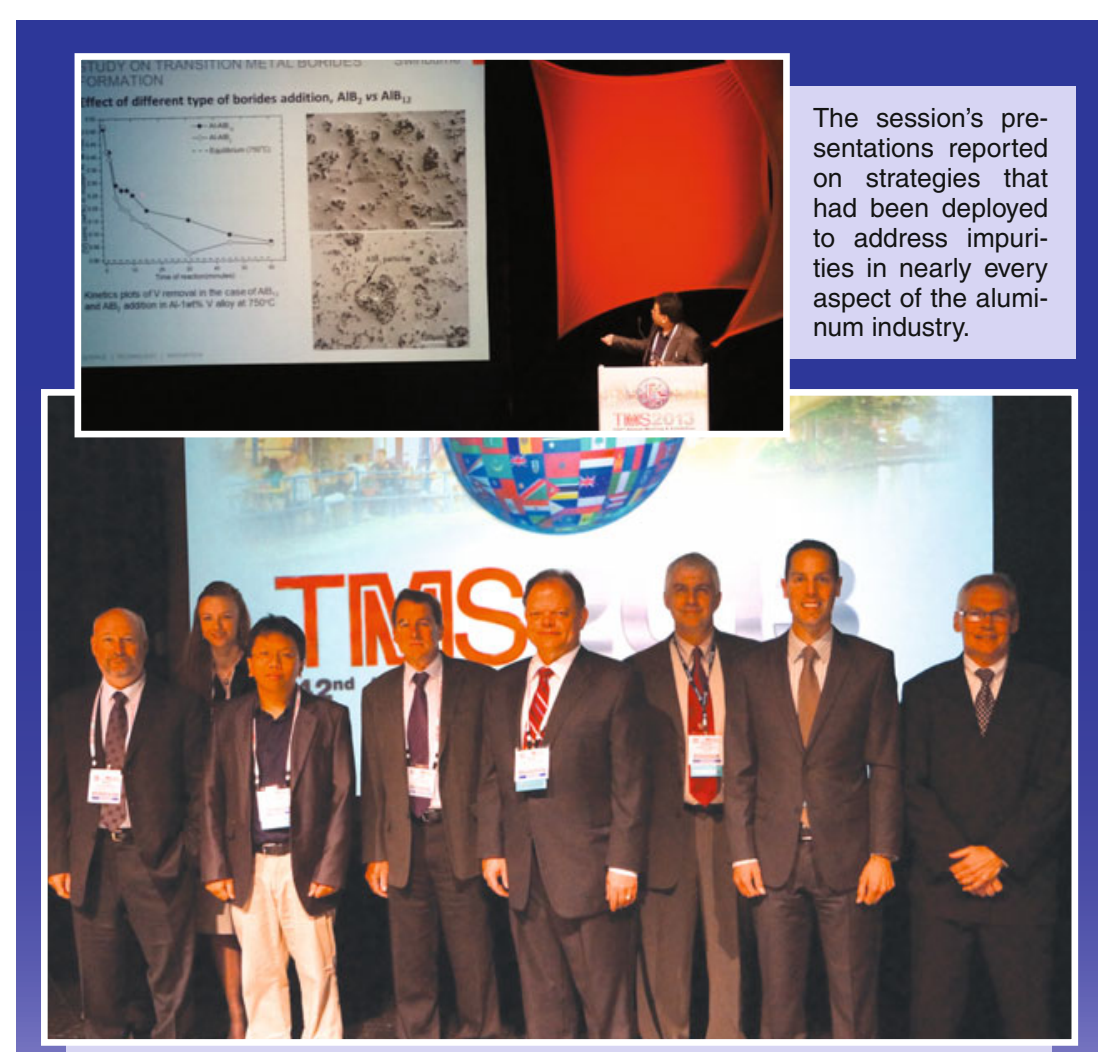

Pictured above are the TMS2013 Aluminum Keynote speakers (L-R): John Grandfield, Grandfield Technology; Andrea Weber, Rio Tinto; Muhammad Rhamdhani, Swinburne University of Technology; James Metson, University of Aukland; Karl Bartholomew, KBC Advanced Technologies; Stephen Lindsay, Alcoa; Stewart Hamilton, New Zealand Aluminum Smelters; Les Edwards, moderator and session organizer.

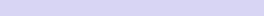

Schneider congratulates Nikhilesh Chawla (R) for being named a 2013 Brimacombe Medalist.

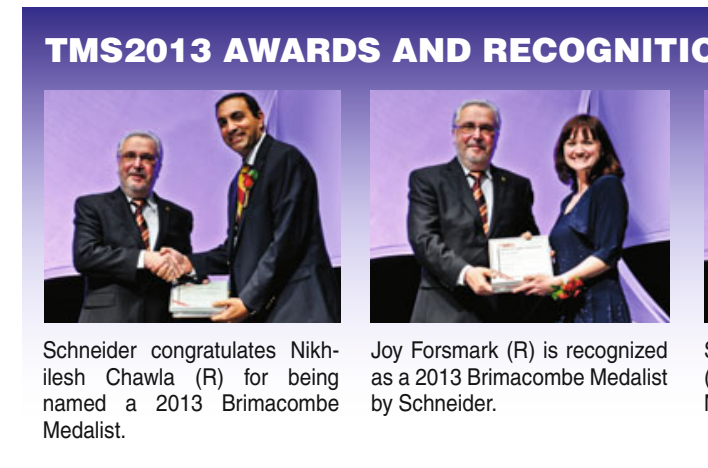

time, Lindsay said. "Impurities have the potential to reshape certain aspects of the design and operation of smelters, electrode plants, cast shops, and refineries," he noted. "Many of the potential outcomes of higher impurities may not require new technology, but different applications of existing technologies."

James Metson, University of Auckland, followed with his presentation, "Impacts of Impurities Introduced into the Aluminium Reduction Cell." Metson looked beyond metal quality, observing, "It is also necessary to consider those impurities which don't report to the metal." While the industry is getting better at some aspects of managing impurities, Metson said, "The neglected part is the electrochemistry and the impacts on the process are considerable. This is driving down our ability to dissolve alumina and tightening the production window."

In the next presentation, "Changes in Global Refining and Its Impact on Anode Quality Petroleum Coke," Karl Bartholomew, KBC Advanced Technologies, Inc., outlined the economic drivers that have profoundly affected the quality and quantity of calcinable anode grade petroleum coke. Of particular significance has been the rapid emergence of shale oil production in the United States.

Andrea Weber, RTA Sebree, then provided an overview of how her company developed and deployed an effective technical improvement plan in "Impact of Higher Vanadium Levels on Smelter Operations." RTA Sebree made a choice to accept increased impurities in one of the primary cokes used in the coke blend supplied to the smelter to secure a significant cost

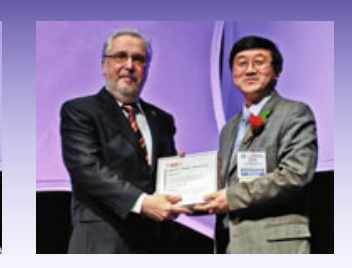

Schneider presents Alan Luo (R) with his 2013 Brimacombe Medal award.

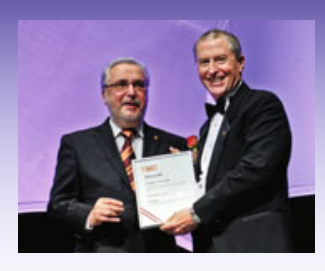

Rusty Gray (R) accepts his 2013 TMS Fellow Award from Schneider.

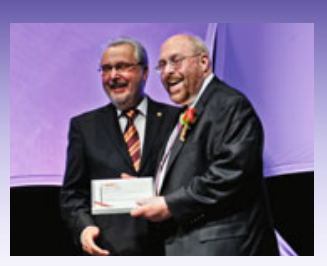

Schneider congratulates Robert Shull $(R)$ for being inducted as a 2013 TMS Fellow. 
discount. Faced with a negative impact on anode consumption, current efficiency, power consumption, and other metrics, RTA developed a work quality management system to ensure that all potline operators, regardless of experience level, were well-trained in basic practices. The project started with a focused analysis of practices in a 42-pot test section. The most critical 20 percent of these procedures were then identified and made the subject of an intensive training session for all operators. A system to monitor individual performance, based on the training program's parameters, was also implemented as a means to identify the need for further coaching. "This illustrates what can be achieved through effective management and people working together," Weber said.

Stewart Hamilton, New Zealand Aluminium Smelters Ltd, also touched on the human factor necessary for success in "Impact on Smelter Operations of Operating High Purity Reduction Cells." Presented as a case study, Hamilton noted that "everyone must be engaged in the mindset," because of the expense and complexity of high purity production. "The good thing about a high purity focus is that it rubs off into other areas," he said. "The more we focus on purity, the more we understand and improve other parameters of smelter operations."

Muhammad Rhamdhani's presentation moved the discussion from the pot room to the cast house. In "Management of Impurities in Cast House with Particular Reference to $\mathrm{Ni}$ and V," he offered an in-depth overview of current and emerging technologies for impurities removal. While these work well for selected elements, he concluded that the boron treatment process for controlling vanadium is not optimized. In addition, no existing technique effectively controls nickel in the cast house. "Strategies through the whole process chain may need to be considered," he said. "And, some fundamental studies need to be carried out."

John Grandfield, Grandfield Technology Pty Ltd, examined the potential impact of impurities on the end product in the final presentation, "An Initial Assessment of the Effects of Increased Ni and V Content in AA6063 and A356 Alloys." He shared an initial investigation conducted for two commonly used alloys, AA6060/6063 and A356, in which castings were produced with low typical levels of $\mathrm{NiV}$, as well as with high NiV levels approaching the maximum P1020 specification of $300 \mathrm{ppm}$ each. While the exact effects depend on the alloy system, Grandfield noted that "vanadium and nickel may have effects even at dilute levels on some properties. We need to start to coordinate with customers so that they do not suddenly find that the properties of their products have changed."

All of the technical papers presented in the keynote session will be published in the Light Metals 2013 proceedings.

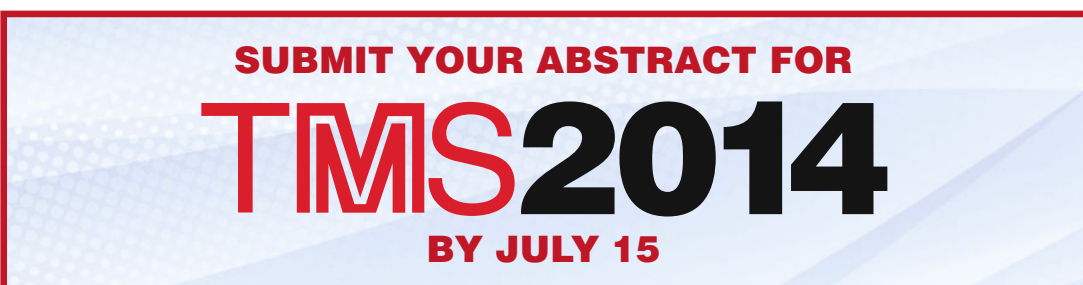

Plan now to be a part of the TMS 2014 Annual Meeting and Exhibition, slated for February 16-20 in San Diego, California. Abstracts are now being accepted until July 15 via ProgramMaster at $h t t p: / / w w w . t m s . o r g / t m s 2014$. A highlight of the conference will be "Celebrating the Megascale: An Extraction and Process Metallurgy Symposium in Honor of David G.C. Robertson." The symposium will feature presentations on the application of engineering principles to metallurgical and materials processing, focusing in particular on metals production and recycling.

Visit the conference website today at http://www.tms.org/tms 2014 for a complete listing of symposia and check back frequently for new programming developments.
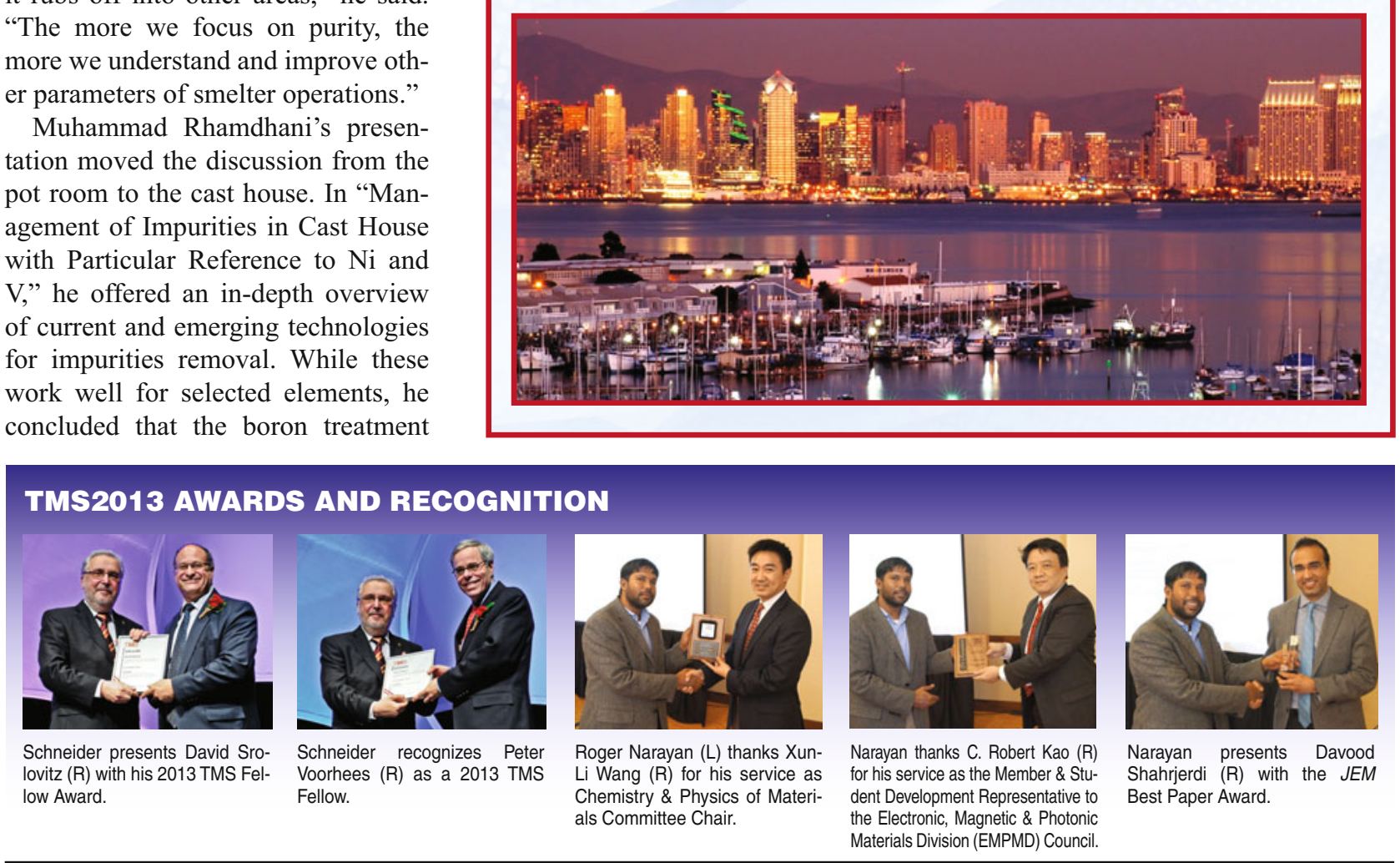


\section{Global R\&D Trends Examined at Acta Materialia Symposium \\ By Alex Leary}

A panel of experts from industry, government laboratories, and academia gathered to discuss issues relevant to global research and development $(\mathrm{R} \& \mathrm{D})$ at Global $\mathrm{R} \& \mathrm{D}$ Trends-Implications for Material Sciences, the Acta Materialia Materials and Society Award Special Symposium. The symposium had been organized as a signature event for TMS2013 to recognize Jeffrey Wadsworth, President and Chief Executive Officer, Battelle Memorial Institute, for being named the recipient of the 2013 Acta Materialia Materials and Society Award.

In his keynote presentation, Wadsworth discussed how trends in global $R \& D$ expenditures are changing along with population growth and industrialization. Wadsworth noted, "For the first time in 2013, the total investment in Asia will exceed U.S. R\&D spending. In the U.S., we spend $\$ 425$ billion on R\&D, and about three quarters comes from industry." $\mathrm{He}$ added, "The U.S. has traditionally led with big science projects. That's changing, and I think that's a mistake. There is lots of money. It's an argument about priorities." He put U.S. priorities into focus by contrasting reluctance to build user facilities like the Large Hadron Collider that cost over $\$ 3$ billion to the $\$ 7$ billion Americans spend yearly on potato chips.

Subra Suresh added his perspective as director of the National Science Foundation (NSF). "Our mandate is not just to support big facilities, but also to support the individual schol-

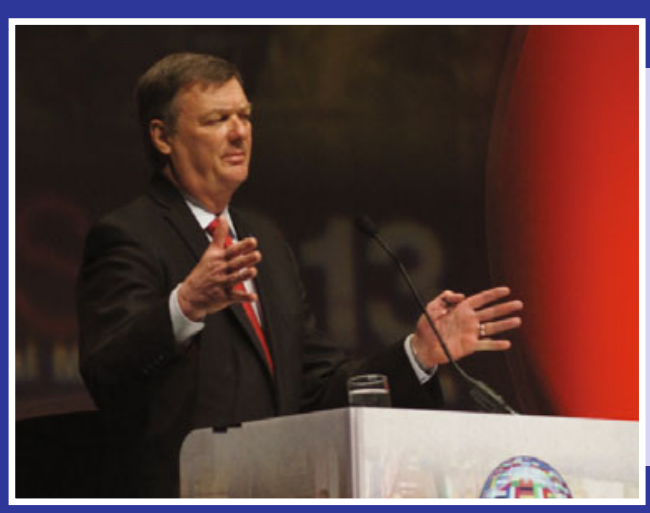

Jeffrey Wadsworth (L), recipient of the 2013 Acta Materialia Materials and Society Award and keynote speaker, outlined trends and implications of current and future global research and development initiatives, along with a prestigious panel (Below) of experts representing industry, government, and academia.
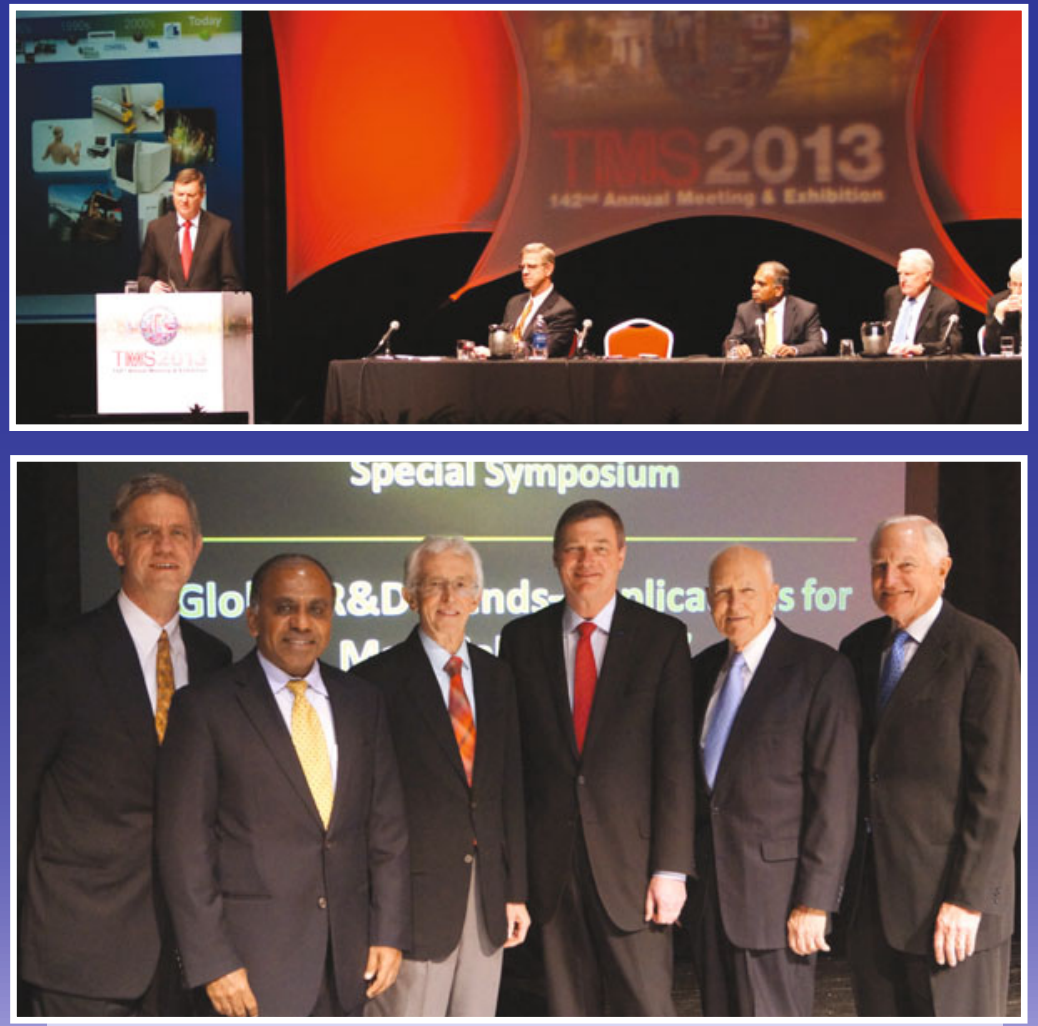

(Above) The Acta Materialia Materials and Society Award Special Symposium speakers $(L-R)$ : Kevin Hemker, moderator and session chair; Subra Suresh, Director, National Science Foundation; Siegfried Hecker, Emeritus Director, Los Alamos National Laboratory; Wadsworth, President and Chief Executive Officer, Battelle; William Nix, Professor Emeritus, Stanford University; Craig Barrett, Retired Chief Executive Officer, Intel Corporation.

\section{TMS2013 AWARDS AND RECOGNITION}

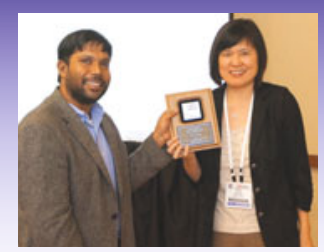

Narayan thanks Fay Hua $(\mathrm{R})$ for her service as the Electronic Packaging and Interconnection Materials Chair.

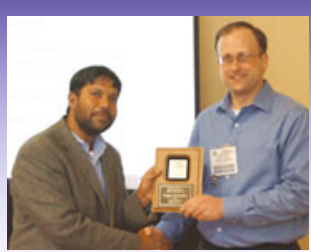

Gregory Krumdick $(\mathrm{R})$ receives thanks from Narayan for his service as the Energy Conversion and Storage Committee Chair.

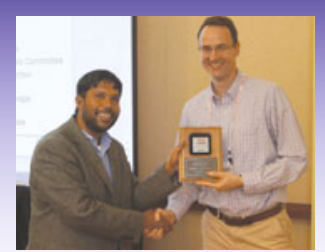

Narayan recognizes Gregory Thompson (R) as the outgoing Nanomaterials Committee Chair.

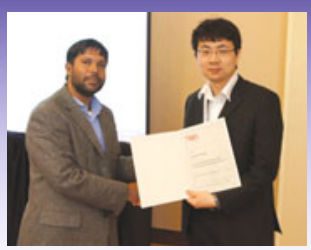

Narayan congratulates Guang Sheung (R) for winning the EMPMD Young Leader Professional Development Award.

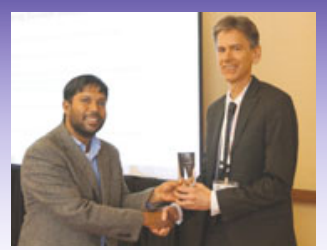

Jeff Hoyt (R) accepts the EMPMD Distinguished Service Award from Narayan. 
ar," said Suresh. He considers funding graduate students, recent postdocs, and new faculty as a top priority for the NSF and is committed to maintaining current funding levels in these areas, despite uncertainty in future budgets. Suresh pointed to the success of previous funding in this area and noted, "The NSF identifies Nobel Prize winning work several decades before the prize committee does."

Suresh also described the creation of a new Global Research Council that aims to address common issues such as peer review, research integrity, ethics, intellectual property rights, and open access to data. This type of council is the first of its kind and Suresh believes that "good science anywhere is good for science everywhere."

Craig Barrett, former Intel chief executive officer, framed his discussion by relating some basic rules for competing in the 21 st century. Regarding recent economic uncertainty, Barrett said, "every time there is a transition, there is an opportunity to win or lose market share. The same is true for countries." He emphasized that "information and money do not know national boundaries" and added, "The 21 st century is the century of innovation. Those people who want to succeed need to participate in that innovation."

Siegfried Hecker, Co-Director, Center for International Security and Cooperation and an emeritus director of Los Alamos National Laboratory, described the state of R\&D in the nuclear industry. A recent decrease in the demand for nuclear power in the United States is affecting the economics of the remaining planned reactors. This decrease is further eroding the U.S. supply chain and the manufacturing base is shifting to Asia. Hecker added, however, that the United States must remain a leader in nuclear regulations.

William Nix, Professor Emeritus, Stanford University, closed the symposium with sage advice regarding research. "It's useful to consider problems from outside your discipline. It's also useful to look for new techniques that end up bettering and nurturing the discipline itself. This not only helps to solve these problems but advances the discipline." He cited several examples and cautioned against, "learning more and more about less and less."

The presentations made at the Acta Materialia Symposium are now available for download as PDFs at http $\therefore / / m a t e r i a l s i n n o v a t i o n . t m s . o r g$ /ActaMaterialaSymposium.aspx.

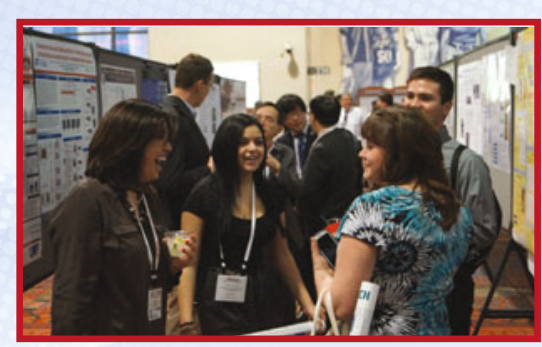

\section{FACE-TO-FACE LEARNING}
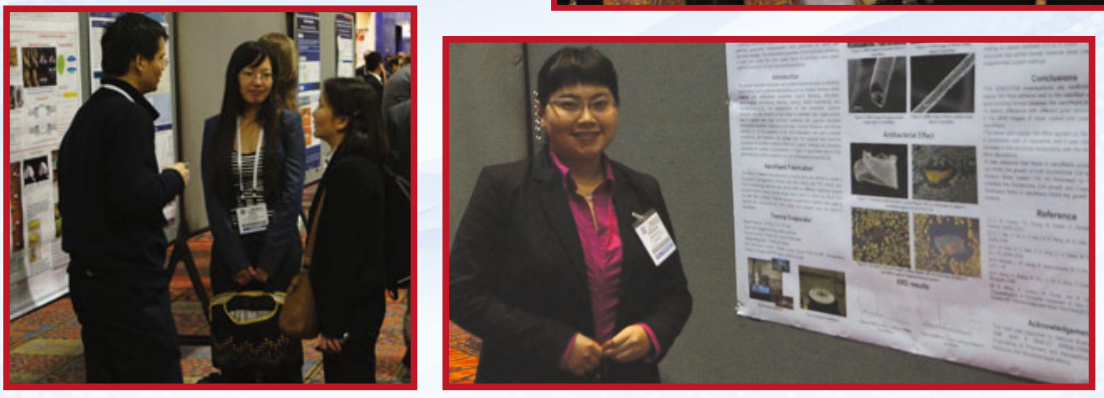

More than 280 technical poster presentations comprised an important component of TMS2013 programming. Networking opportunities scheduled as part of the poster session enabled researchers to provide individualized discussions of their work and answer questions in detail to a wide range of Annual Meeting attendees.
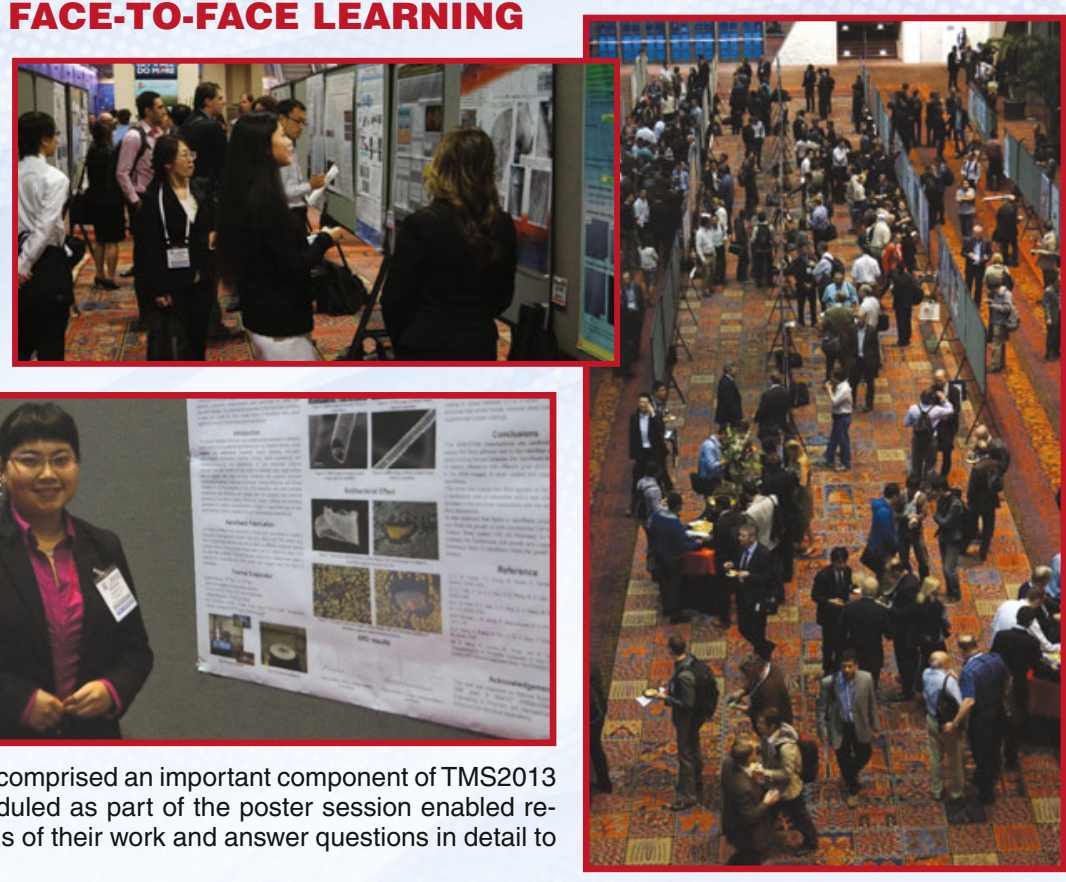

\section{TMS2013 AWARDS AND RECOGNITION}

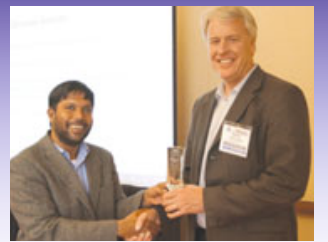

Mark Asta (R) receives the EMPMD Distinguished Scientist/Engineer Award from $\mathrm{Na}$ rayan.

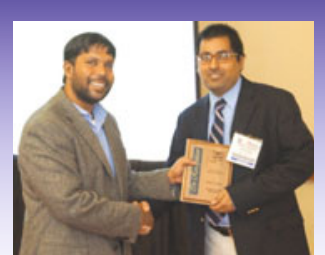

Narayan thanks Nitin Chopra (R) for serving as EMPMD Education Representative.

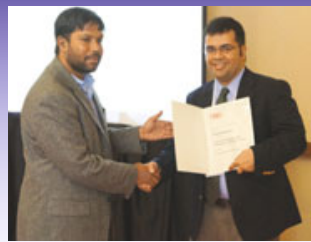

Sarbajit Banerjee $(\mathrm{R})$ receives the EMPMD Young Leader Award from Narayan.

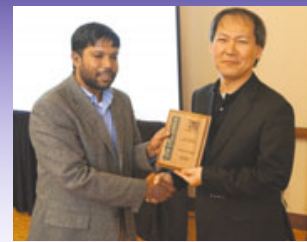

Narayan thanks Seung $H$. Kang (R) for his service as EMPMD Programming Representative.

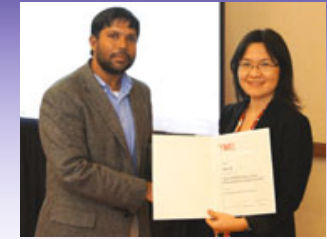

Narayan congratulates Yue Qi (R) on her EMPMD Young Leader Award. 


\section{Environment, Energy, and Economics Shape Discussion on Nickel-Cobalt Production By Alex Leary}

TMS2013 hosted the International Nickel-Cobalt Symposium, bringing together the world's experts in nickel and cobalt production. In the opening plenary session, Gary Coates and David Weight, respectively from the Nickel Institute and the Cobalt Development Institute, described the historical development, major material classes, and wide range of applications benefiting from these elements.
Stainless steel accounts for $65 \%$ of Ni usage annually and the Nickel Institute recently celebrated the 100th anniversary of Maurer and Strauss's patent with an exposition in Beijing last May. Cobalt is typically a byproduct of other manufacturing processes and demand for cobalt production increased by $5 \%$ over the last 10 years, according to Weight. Rechargeable batteries account for the largest usage per year of cobalt, recently surpassing its usage in superalloys.

Joe Ferron described cobalt recycling techniques, many currently practiced by industry. "The most efficient method for recycling is to re-melt the

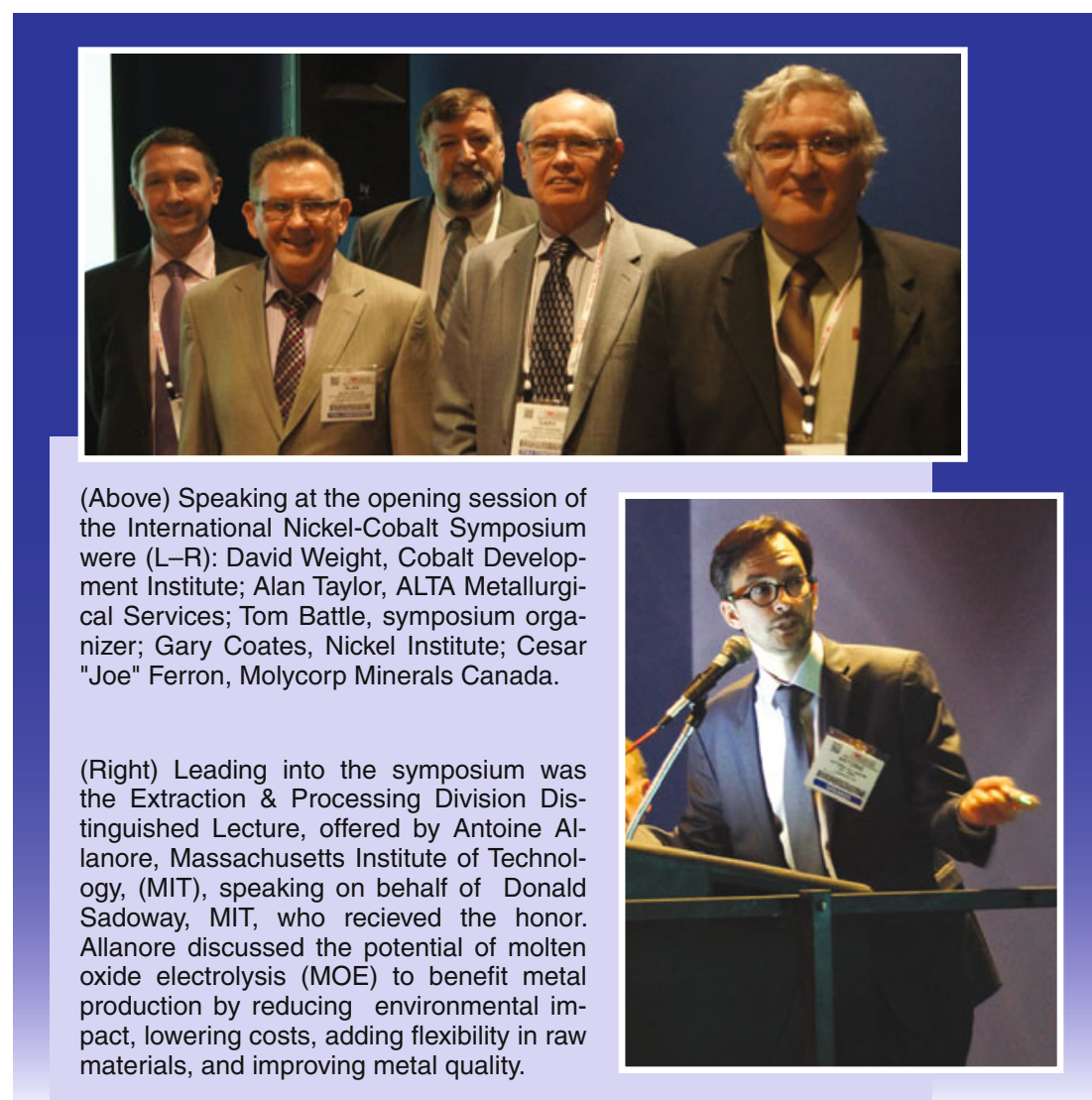

scrap at the source," said Ferron, but he continued to show potential value in recycling from other sources including Co-based catalysts, spent batteries, and various wastes from primary cobalt production. While he believes that the technical challenges to cobalt recycling have largely been solved, the current Co recycling rate of $32 \%$ is limited by economic factors, such as the costs to sort and transport spent materials. Comparatively, primary production methods remain the more attractive option over recycling. However, as the copper belt in central Africa contains nearly half of the world's known cobalt reserves, difficulties arising from regional instability may affect prices considerably.

Availability of sulphides, the traditional source ore for nickel production, is also decreasing. Alan Taylor of ALTA Metallurgical Services described production methods based on laterites, an alternative ore source. Most of the operations currently processing laterites use a sulphate process that is well known, but requires complex downstream processing. Alternative methods using chloride and nitric acids have been tested, but have not yet been commercialized. The advantages and disadvantages of each technique vary, especially since ore bodies are not necessarily located near cheap useful energy sources. Taylor encouraged further research into these processes.

Held every four years, the International Nickel-Cobalt Symposium for 2013 was organized by the TMS Extraction and Processing (EPD) Division and the Metallurgy and Materials Society (MetSoc) of the Canadian Institute of Mining, Metallurgy, and Petroleum (CIM).

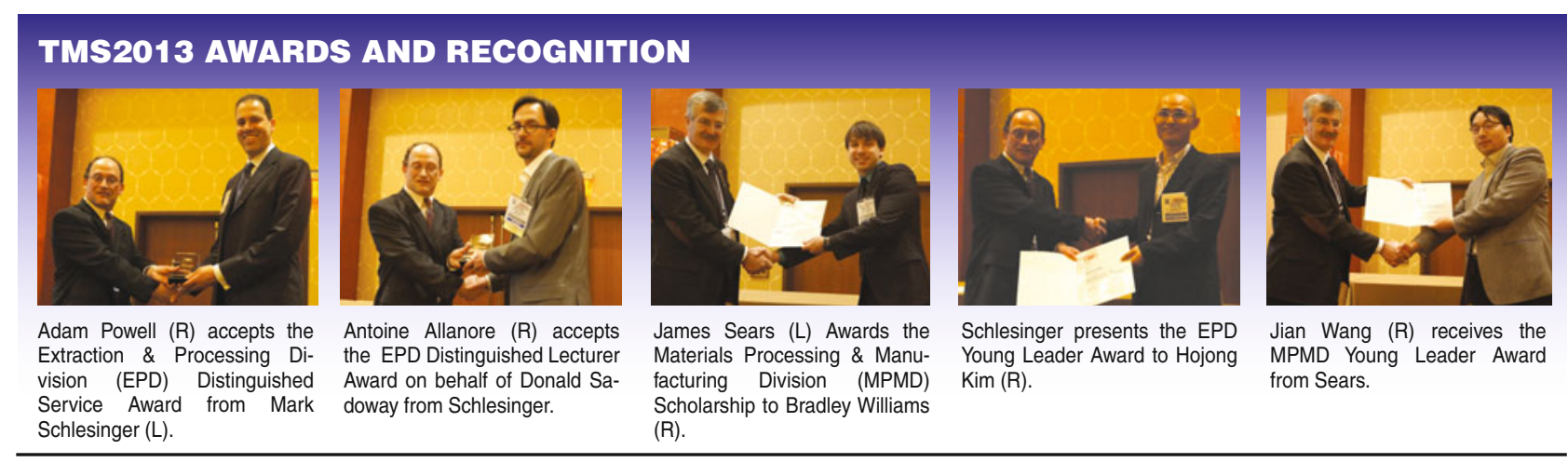




\section{Special Plenary Looks at Innovation in Materials and Manufacturing By Graham Sanborn}

Four high-level government and academic professionals presented at a special plenary focused on innovation initiatives for rapid commercialization in materials and manufacturing.

Julie Robinson, NASA's Chief Scientist of the International Space Station (ISS), kicked off the session with her presentation, "The ISS as an Innovation Laboratory." Robinson explained how researchers and industry should use the ISS for experiments to promote innovation. The ISS is able to support about 200 experiments at once and its lifetime is just beginning. Robinson also reviewed how the ISS and other microgravity systems have a history of promoting experiments that directly accelerate the transfer of knowledge into industrial processes.

Frank Gayle, Deputy Director, Advanced Manufacturing National Program Office, National Institute of Standards and Technology (NIST), and Robert Ivester, Deputy Program Manager, Advanced Manufacturing Office, U.S. Department of Energy, both presented on innovation related to the Advanced Manufacturing Partnership (AMP).

The AMP initiative includes plans for developing 15 manufacturing hubs that are linked in regional clusters across the United States, promoting innovation between businesses and academia, as well as workforce development and education. Gayle highlighted a pilot initiative called the National Additive Manufacturing Innovation Institute.

Ivester explained that motivations for these new initiatives are a result of the
United States' falling behind in economic competitiveness and a growing U.S. high-tech trade deficit. The AMP aims to promote economy-wide life cycle impacts, with goals to reduce life cycle energy consumption of manufactured goods by $50 \%$ over ten years. Both AMP offices are directing efforts to bridge the current funding gap between basic science and prototyped technology.

Tresa Pollock, Alcoa Professor of Materials and Chair of the Materials Department at the University of California at Santa Barbara, presented a talk on "Integrated Computational Materials Engineering (ICME): A Study on Implementing ICME in the Aerospace, Automotive, and Maritime Industries." She provided an update on a study be- ing led by TMS on the implementation of ICME. The study is intended to serve as a field manual for practitioners to implement ICME and is centered on lightweight applications in the aerospace, automotive, and maritime sectors. The ICME implementation study is being developed by five teams made up of experts from industry, government, and academia in each of the sectors, and will be completed for presentation at the ICME 2013 conference in July 2013.

The plenary was supported by the Georgia Tech Manufacturing Institute and the Georgia Tech Institute for Materials. Presentations made at this symposium are available for download as PDFs at http://materialsinnovation.tms.org /2013MaterialsInnovationPlenary.aspx.
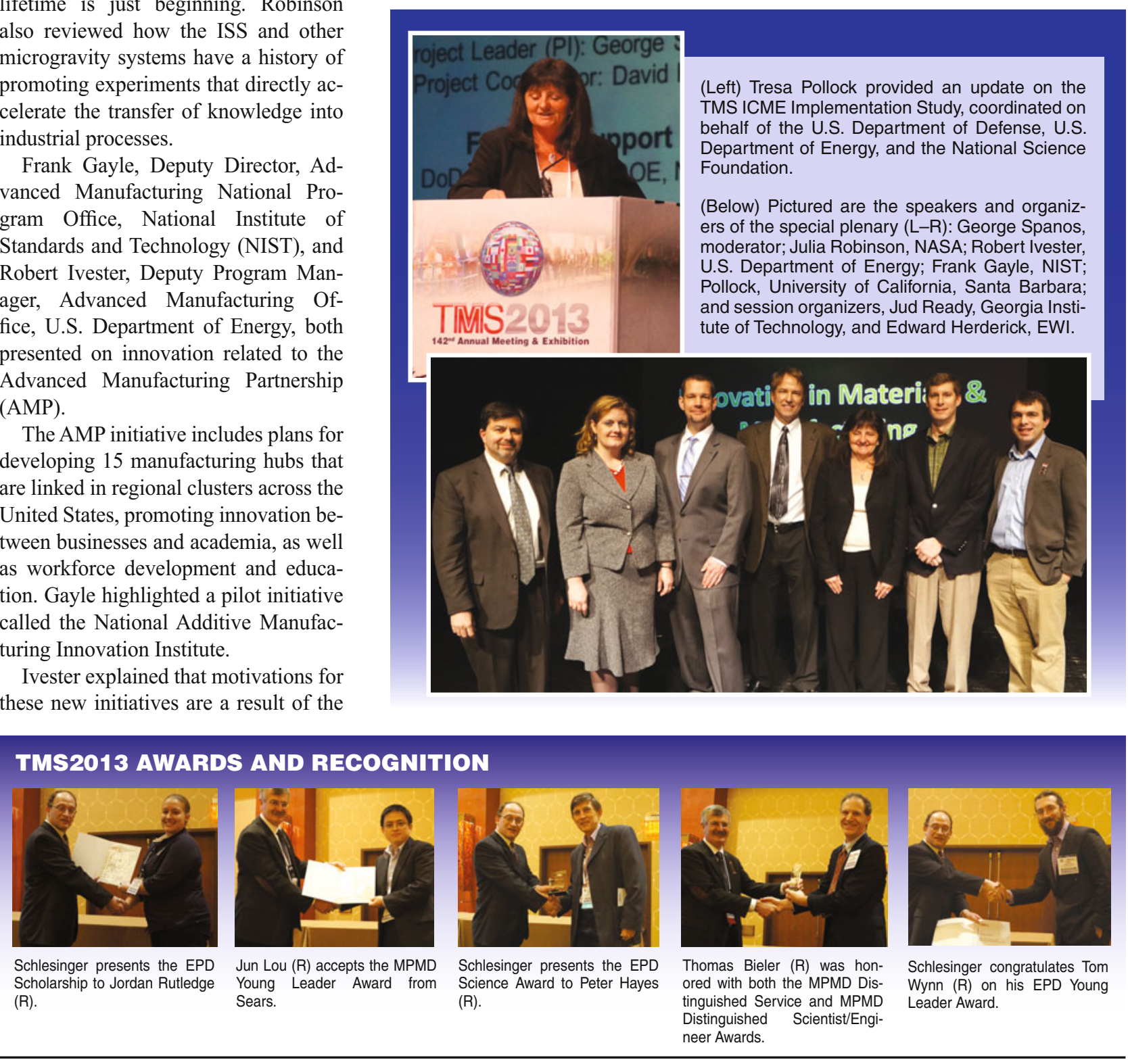


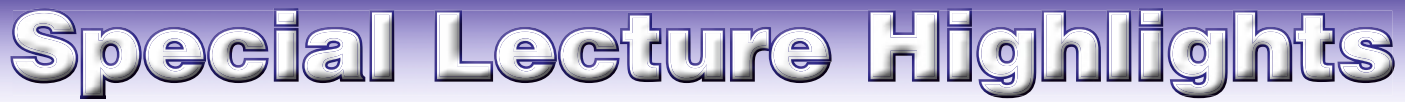

\section{TUNABLE NANOSTRUCTURES}

Delivering the 2013 Institute of Metals/Robert Franklin Mehl Lecture was Horst Hahn, Managing Director, Institute for Nanotechnology, Forschungszentrum Karlsruhe. Hahn described his work in tunable nanostructures and printable electronics, in which he employs a gating mechanism where properties such as length, conductivity, and magnetization can be reversibly controlled by an external field. Hahn also discussed applying a type of property control-well known in semiconductors - to metals that requires small dimensions where charge screening influences conduction electrons and is amplified through the use of a nanoparticulate structure. Hahn said that he avoids contact issues in the porous media by surrounding it in an electrolyte. The devices defy common limitations of electrolytic materials that typically show slow response times by operating at $10 \mathrm{MHz}$ and using inorganic materials to improve stability.

Hahn reported that his research demonstrates the ability to tune responses by affecting the hole concentration through the use of an external field, as opposed to compositional adjustments. He noted that the performance of an indium oxide

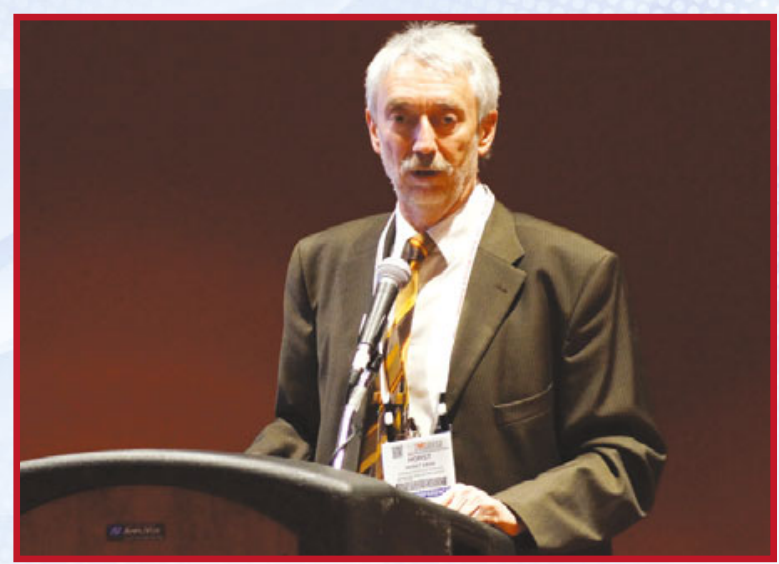

Horst Hahn, "Tunable Nanostructures and Printed Electronics" device, similar to a field effect transistor with low threshold voltages, exhibited large resistivity changes.

-Reported by Alex Leary

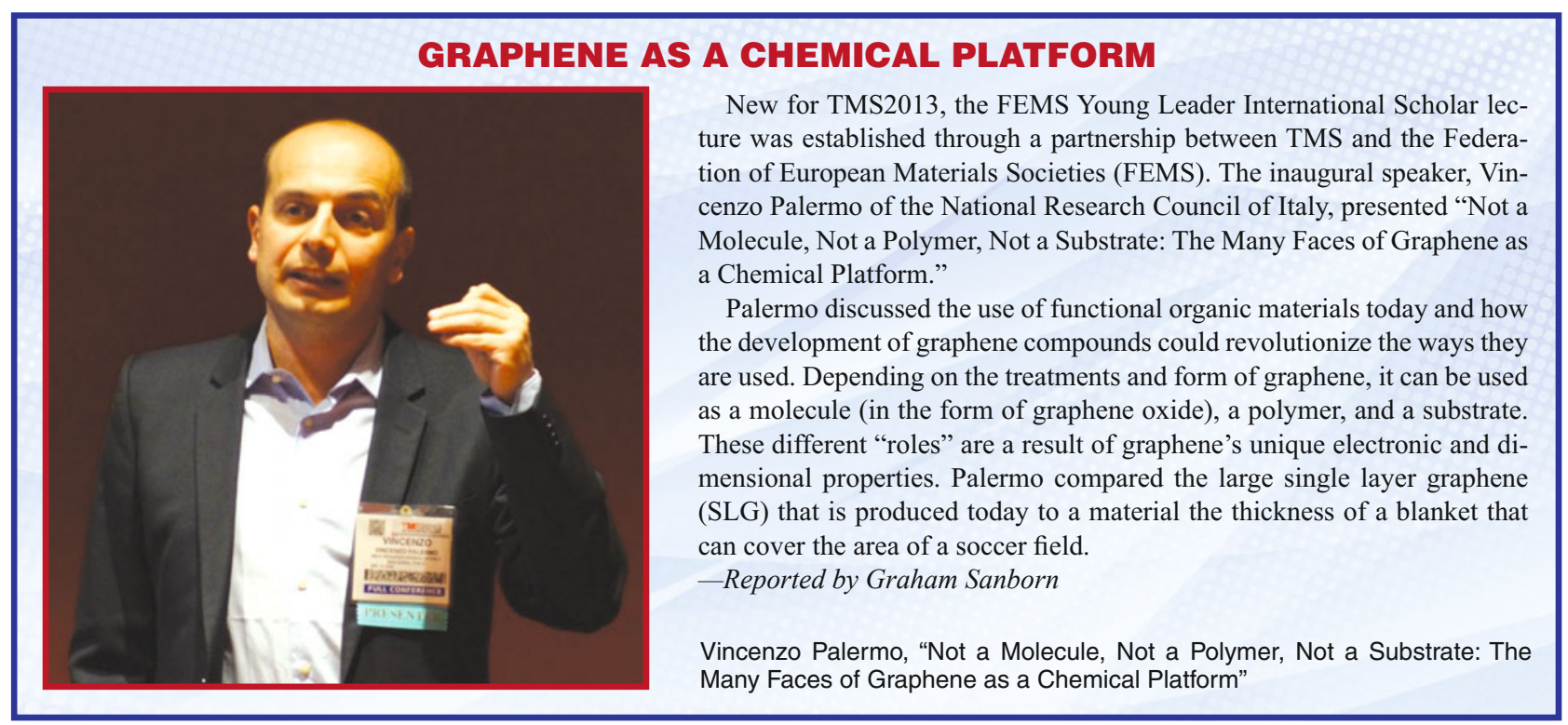

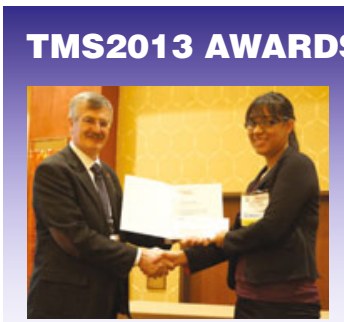

Veronica Perez $(R)$ is awarded the MPMD Scholarship by Sears,

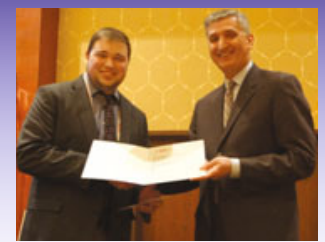

John Hryn (R) presents Rodney Lee Jones $(L)$ with the Light Metals Division (LMD) Scholarship.

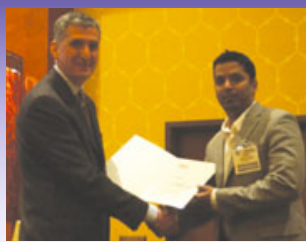

Hryn congratulates Kiran Solanki $(\mathrm{R})$ on his LMD Young Leader Award.

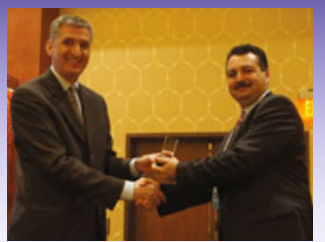

Dmitry Eskin $(\mathrm{R})$ receives the LMD Technology Award from Hryn.

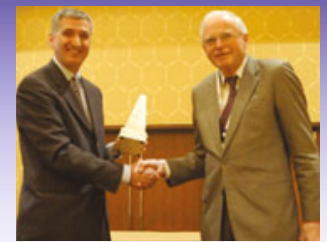

Jomar Thonstad (R) accepts the LMD Distinguished Service Award from Hryn. 


\section{WORK-LIFE BALANCE}

Julia Greer, Assistant Professor, California Institute of Technology, gave an inspiring presentation on how academic professionals can manage the demands of family, friends, and career at the Young Leader Tutorial Luncheon Lecture to a room full of young and aspiring scientists. The main issue with any busy professional, she noted, is that "you have to make personal sacrifices to achieve career aspirations." She stressed that it is important to learn how to balance these sacrifices so that they don't interfere with your personal life and goals.

Greer condensed the research, advice, and personal experience she has learned into a top ten list of survival strategies for managing a life-work balance. Topics and examples included finding balance by clarifying values and setting priorities (and not feeling guilty about giving something low priority); using business practices in family (weekly all-hands meeting anybody?); avoiding "martyrdom addiction" and perfectionism by learning to compromise on the low priorities and delegate; having a supportive partner and lifestyle; and, most importantly, not taking yourself too seriously.

-Reported by Graham Sanborn

Julia Greer, "A Scientist, a Parent, a Teacher, a Mentor... How to Balance it All?"

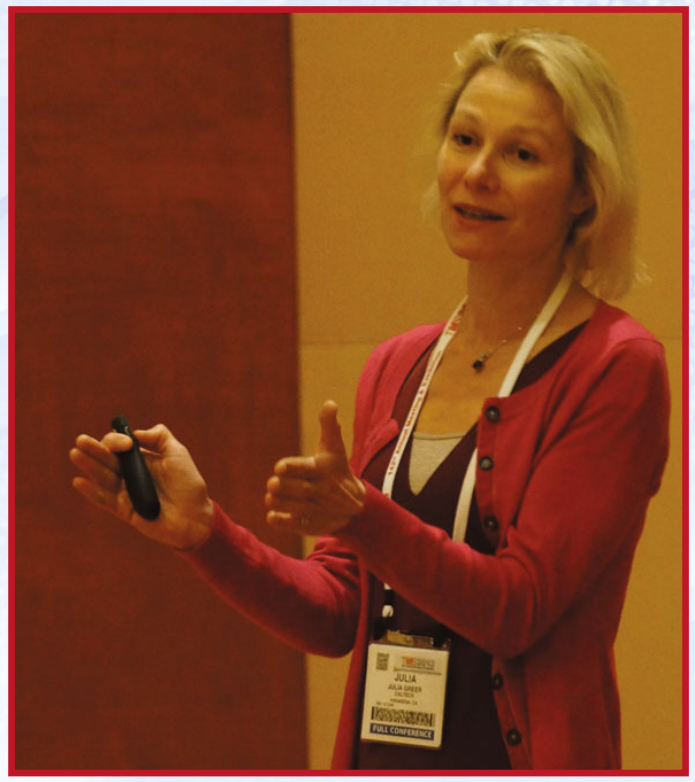

\section{IT IS ROCKET SCIENCE. . .}

Leon Prentice, Senior Research Engineer, CSIRO Process Science and Engineering, and winner of the Vittorio de Nora Prize for Environmental Improvements in Metallurgical Industries, presented "It Is Rocket Science: The Engineering and Impact of Carbothermal Magnesium Technology" during the Energy Technologies and Carbon Dioxide Management: Carbon Footprint Analysis symposium.

In discussing recent work on MagSonic ${ }^{\mathrm{TM}}$, a carbothermal magnesium refinement process, Prentice focused on economic assessments in preparation for scale up and contrasted the process to the currently adopted techniques in industry: the Pidgeon process and electrolytic extraction. He advised caution with regards to process economics adding, "There are a lot of different claims in the literature. They tend to only focus on one part of the process. So the main advantage of MagSonic derives from its simplicity." MagSonic uses a Laval nozzle - historically utilized in rocket engines for propulsion - to "shock quench" the gases and solving the reversion reaction, a traditional limitation of thermocarbon processes. "MagSonic is likely to be more expensive than Pidgeon due to the reactors and the vacuum system," said Prentice, but he predicted $50 \%$ less energy intensity and $85 \%$ less global warming potential (GWP) gases. -Reported by Alex Leary

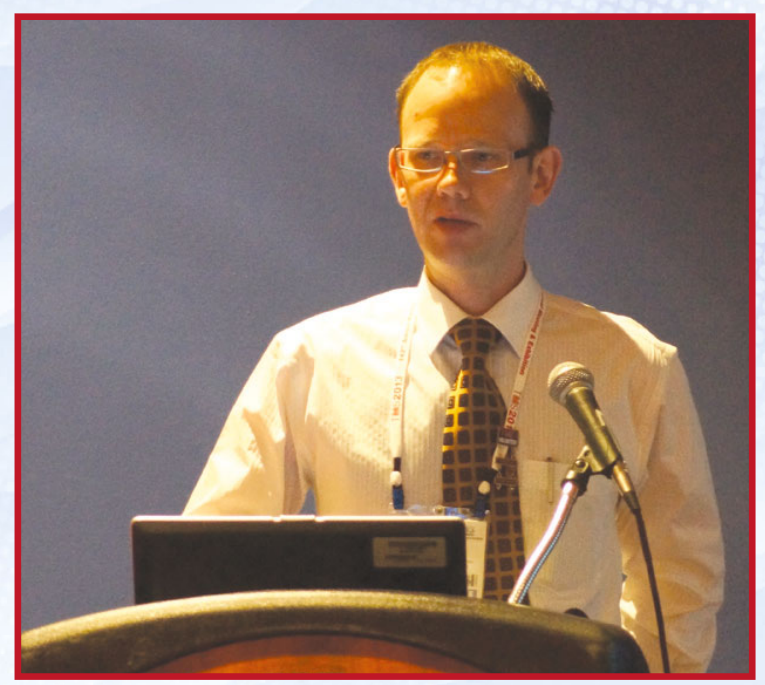

Leon Prentice, "It Is Rocket Science: The Engineering and Impact of Carbothermal Magnesium Technology"

\section{TMS2013 AWARDS AND RECOGNITION}

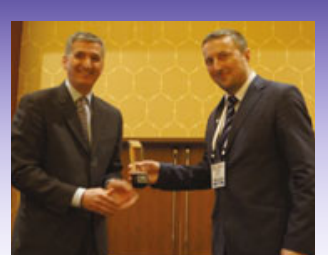

Hryn presents Andrey Panov (R) with the Light Metals Best Paper Award.

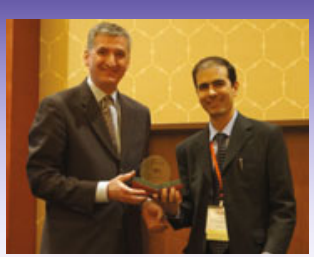

Mansoor Barati (R) accepts the LMD JOM Best Paper Award from Hryn.

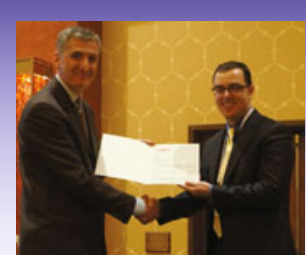

Hryn congratulates James Saal (R) on his LMD Young Leader Award.

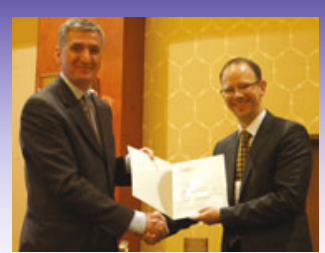

Leon Prentice $(R)$ receives the LMD Young Leader Award from Hryn.

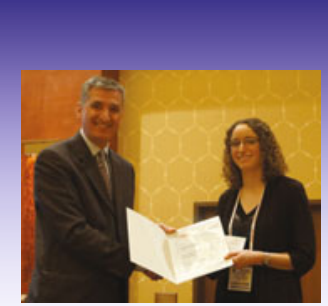

Hyrn presents Marissa Lafata (R) with the LMD Scholarship. 


\section{SUSTAINABILITY: A PARADIGM SHIFT FOR METALS}

Maurits Van Camp, Director of Competency Platform Recycling and Extraction at Umicore, presented "Sustainability: A Paradigm Shift for Metals" at the Extraction \& Processing/Materials Processing \& Manufacturing Division (EPD/MPMD) Luncheon. Van Camp emphasized the need for wide collaboration. "You need to be good at all the steps," said Van Camp, referring to the compounding efficiency losses by each step in the recycling chain, "and you need to talk to everyone."

$\mathrm{He}$ described the process flow for a smelting plant in Antwerp that recovers metals from electronic scrap and a recently completed $\$ 25$ million battery recycling plant. Van Camp believes there are many opportunities in the collection phase and that "sustainability, in the end, will create jobs." Regarding the challenges ahead, Van Camp stated, "How will we realize the paradigm shift? The aim is clear, the strategy is being developed, the knowledge is being created, and entrepreneurs are needed to translate the knowledge into innovative market solutions."

-Reported by Alex Leary

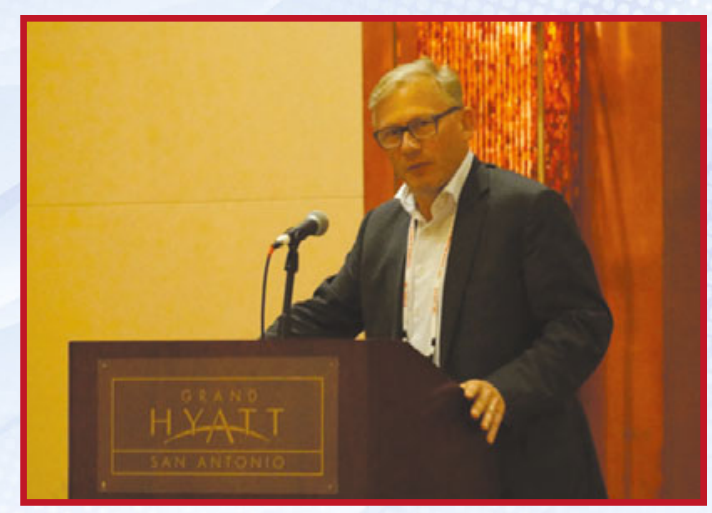

Maurits Van Camp, "Sustainability: A Paradigm Shift for Metals"

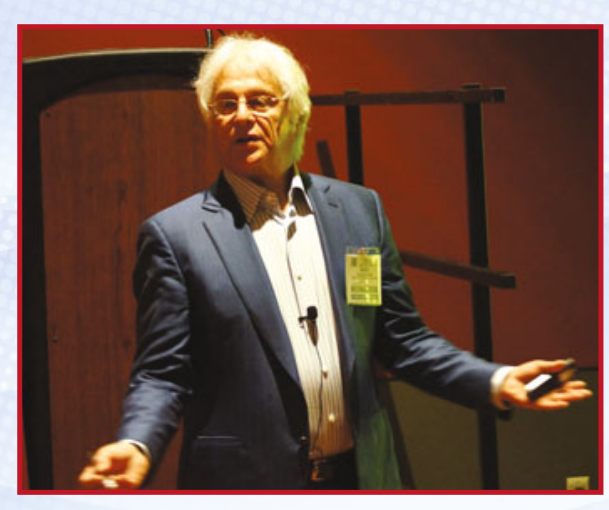

\section{FIRST PRINCIPLES ALLOY THEORY}

Alex Zunger, Professor, University of Colorado, Boulder, delivered the William Hume-Rothery Award Lecture, "First Principles Alloy Theory-A Retrospective." Zunger has made seminal contributions as a theorist working in the area of condensed matter and materials physics, including the development of theory methodologies that enabled prediction of a wide range of properties of solids, even before they were measured. His lecture covered the development of foundational "tools of the trade," through first-principles thermodynamics and computational discovery of new materials, in the areas of metal alloys, semiconductor alloys, and insulator alloys.

Alex Zunger, "First Principles Alloy Theory"

\section{LITHIUM AS AN ENERGY SOLUTION}

Among many highlights at the Light Metals Division Luncheon was a talk offered by John Mitchell, President, North American Rockwood Lithium, on the role of lithium in addressing global energy issues. Within the context of work being done at Rockwood, Mitchell provided an overview of the current status of electric vehicles and the increasing impact of automobile air pollution on the global environment and health. He also presented economic and geopolitical factors that have created challenges for lithium production and development and noted that the value of lithium in ensuring energy security goes beyond batteries. The growing use of aluminum lithium alloys for weight reduction in aerospace and the addition of lithium salts to save energy when operating melt furnaces were among the examples that he cited.

--Reported by Graham Sanborn

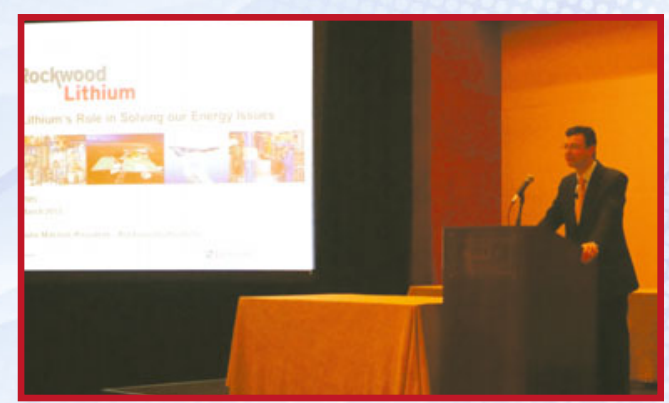

John Mitchell, "Lithium: Solving Global Energy Issues"

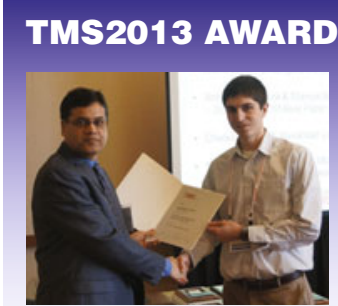

Rajiv Mishra (L) awards Alexander Lohse (R) the Structural Materials Division (SMD) Scholarship.

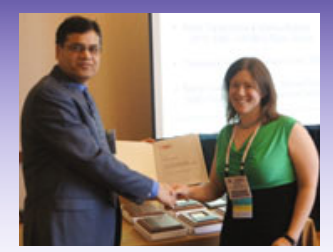

Mishra congratulates Alexis Lewis $(\mathrm{R})$ on her SMD Young Leader Award.

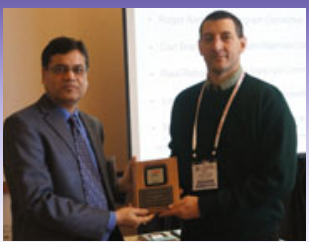

Mishra thanks Carl Boehlert ( $R$ ) for his services as Computational Materials Committee Chair.

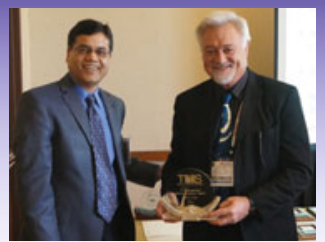

Carlos Tomé $(R)$ accepts the SMD Distinguished Scientist/ Engineer Award from Mishra.

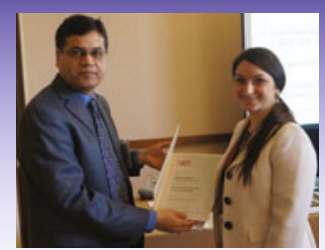

Mishra awards Chelsea Ehlert (R) the SMD Scholarship. 


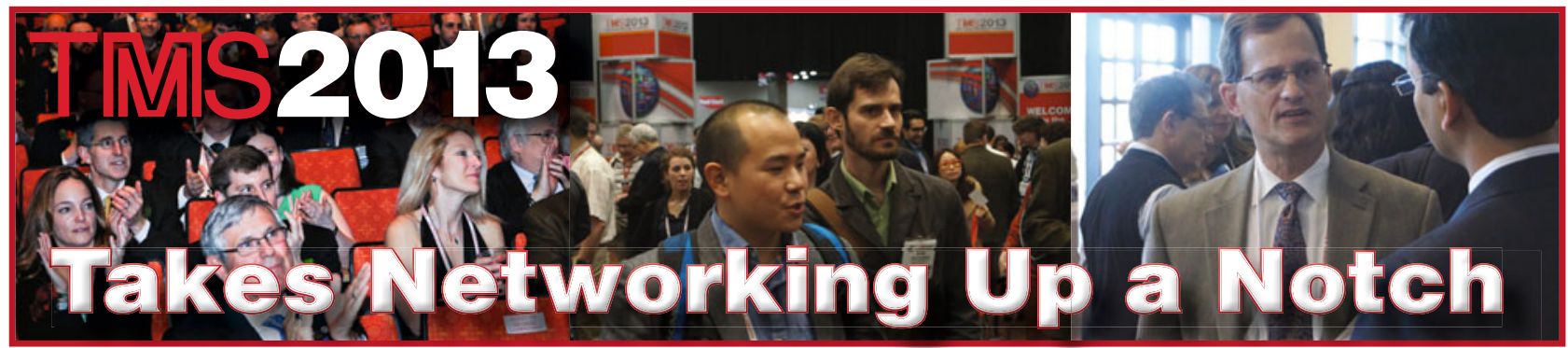

Sharing months - and even years of accumulated knowledge - in less than half an hour during a symposium session can be challenging. For this reason, the learning often just begins within the walls of a session room for many TMS Annual Meeting attendees. The chance and informal conversations that explore ideas with colleagues in more depth, while also laying the groundwork for possible collaborations, stand among the greatest benefits of professional conference attendance.

To continue enhancing the value of the TMS Annual Meeting experience, several new and improved networking opportunities were introduced at TMS2013. A particularly well received one was a reception, hosted by James J. Robinson, TMS Executive Director, for members who have attended ten or more consecutive Annual Meetings. "It was simply a pleasure to see so many old friends, and in some cases, getting to put names to some faces that I've long seen, but never met," said Robinson. "These folks are the infrastructure of the Annual Meeting, and I was pleased to be able to thank them in this small way."

In the category of retooled networking opportunities, the Young Professionals Happy Hour Reception was clearly a winner. While TMS has hosted receptions for its early career

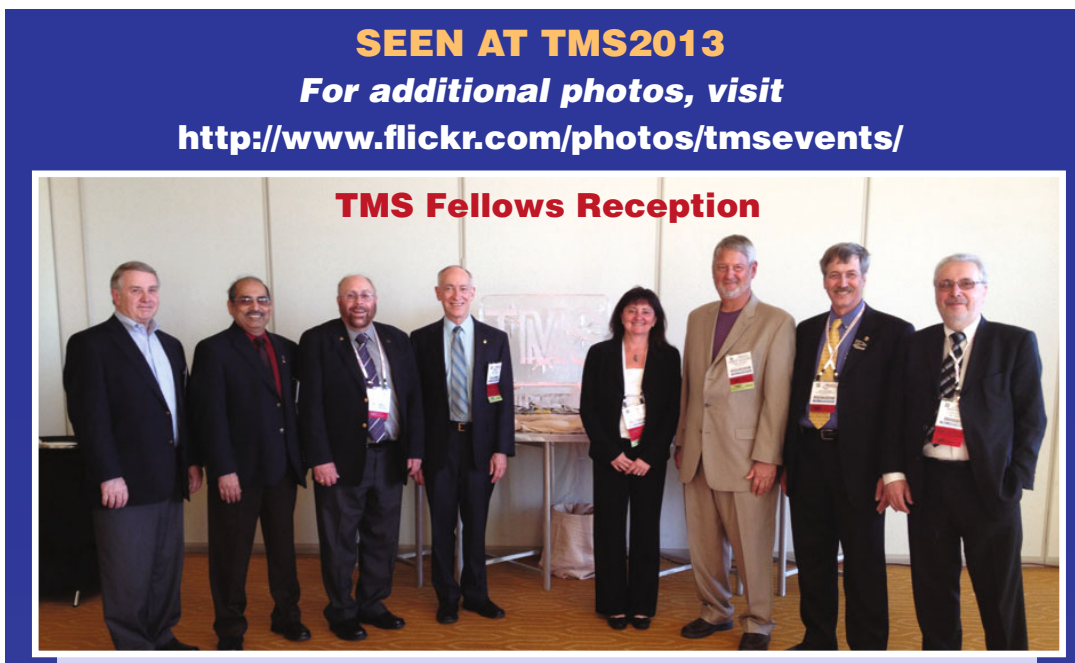

(Above) TMS Presidents representing several decades gathered to catch up with friends and colleagues at the TMS2013 Fellows Reception. Pictured are (L-R): J. Wayne Jones (1999); Brajendra Mishra (2006); Robert D. Shull (2007); Garry Warren (2011); Tresa Pollock (2005); Rob Wagoner (1997); Ray Peterson (2009); and Wolfgang Schneider (2012).

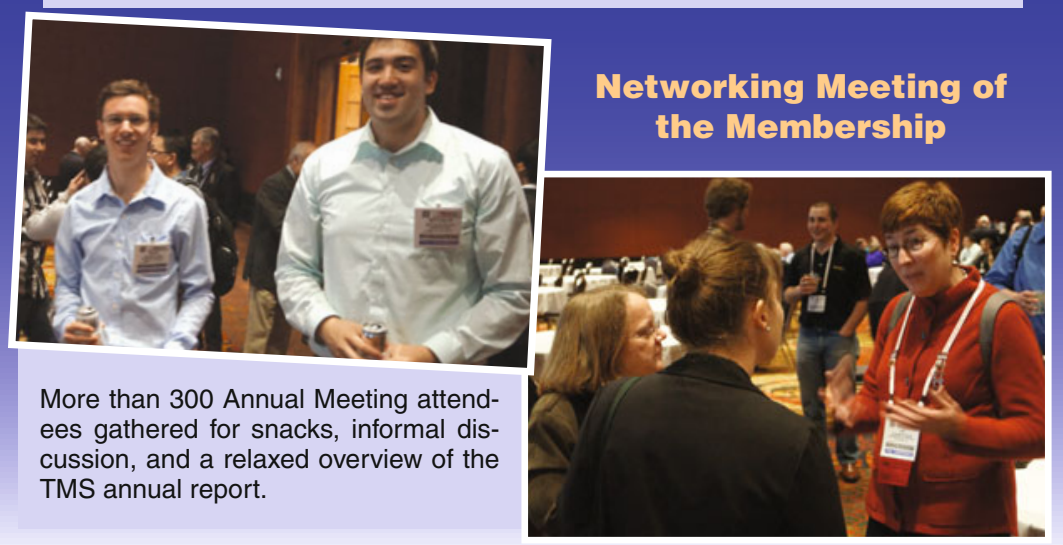

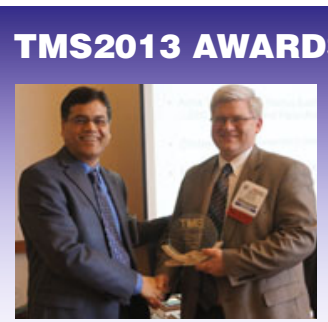

David Bahr $(\mathrm{R})$ receives the SMD Distinguished Service Award from Mishra.

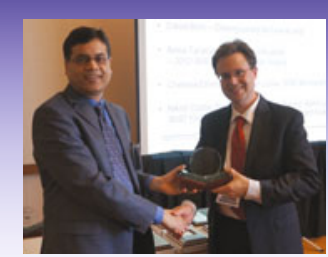

Markus Buehler (R) accepts the SMD JOM Best Paper Award from Mishra.

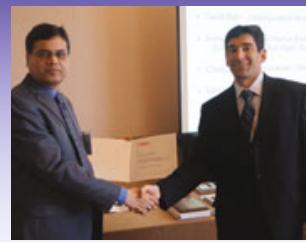

Mishra presents Michael Sangid (R) with his SMD Young Leade Award.

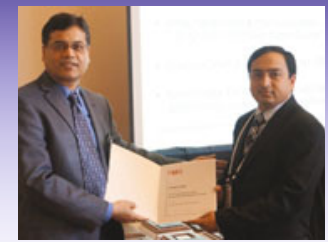

Nikhil Gupta $(R)$ receives his SMD Young Leader Award from Mishra.

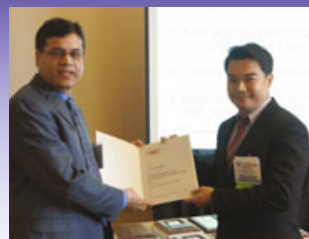

Mishra congratulates Po-Yu Chen $(R)$ on his SMD Young Leader Award. 


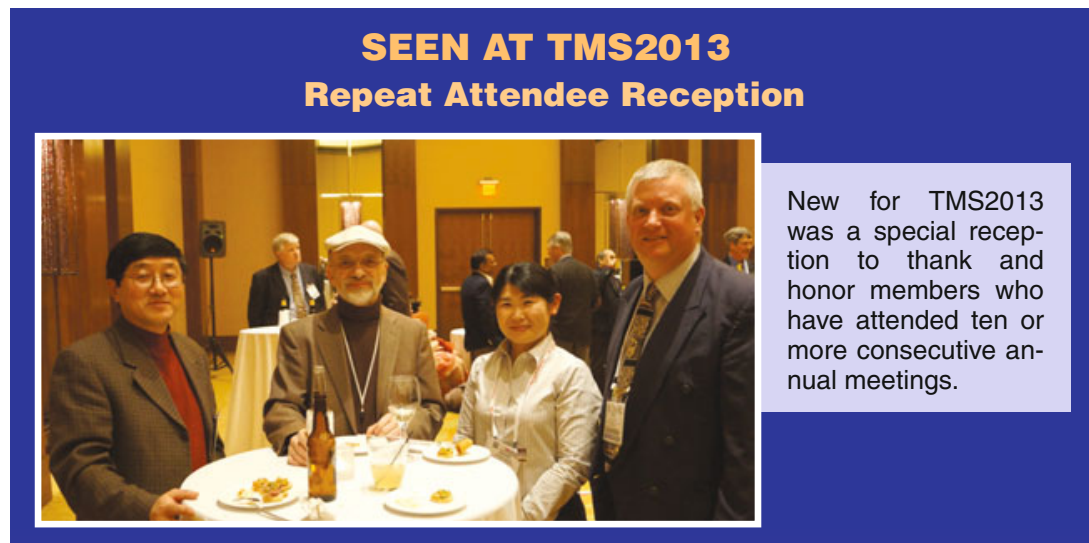

Women in Science Breakfast

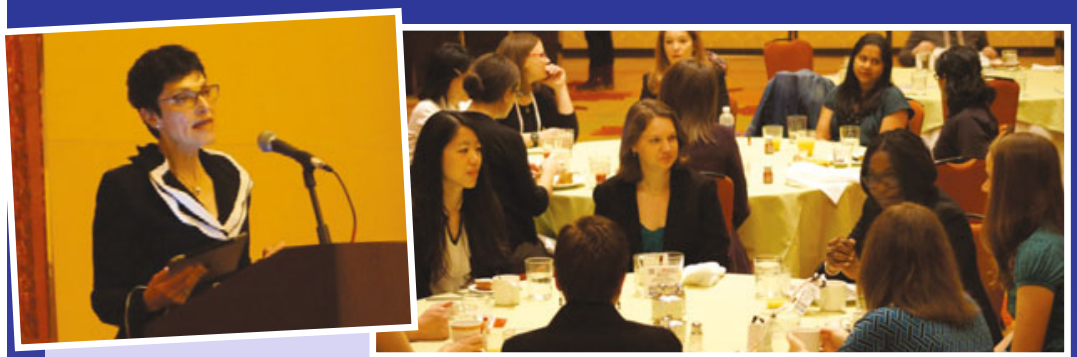

(Above left) Mary Juhas, Chair of the TMS Women in Science Committee, welcomed participants (above right) and encouraged them to share their insights with each other on an array of career-related topics.

\section{TMS-AIME Awards Banquet}
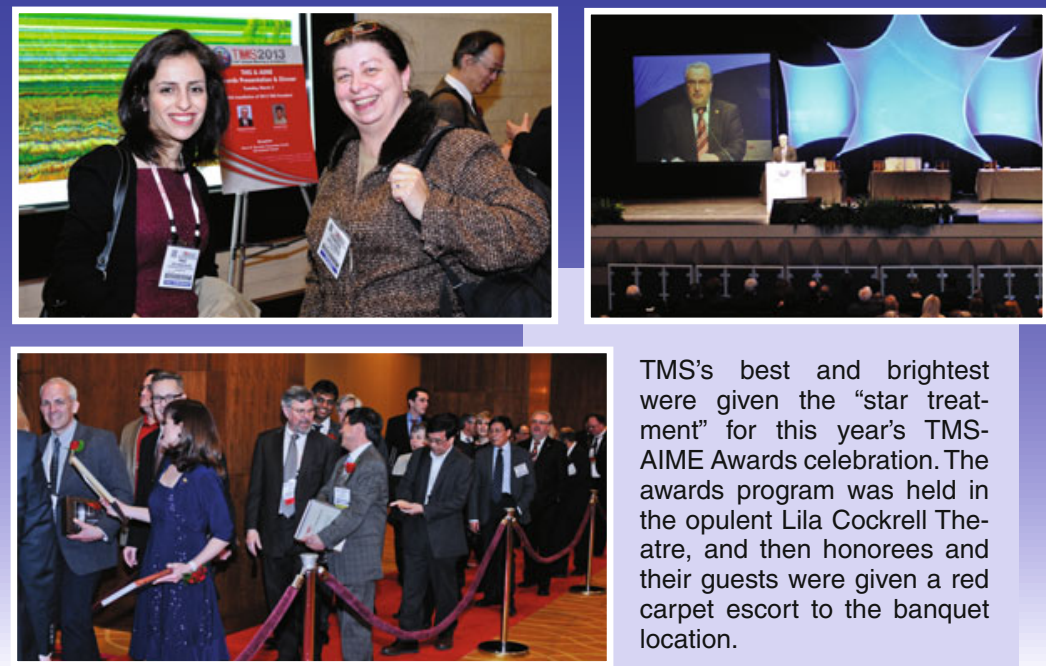

TMS's best and brightest were given the "star treatment" for this year's TMSAIME Awards celebration. The awards program was held in the opulent Lila Cockrell Theatre, and then honorees and their guests were given a red carpet escort to the banquet location. professional members for years, this marked the first time that more seasoned members had been asked to join in the event. This expansion of the invitee list was made based on suggestions from up-and-coming TMS leaders for additional opportunities to network with more experienced professionals. Jennifer Carter, Assistant Professor, Case Western Reserve University, noted that she appreciated the ability to mingle with TMS leadership in a relaxed, casual setting. "It makes you feel valued," she said.

The approach taken at TMS2013 with the Networking Meeting of the Membership also transformed a lightly attended event from previous years into a lively gathering of more than 300 Annual Meeting attendees. "2012 was a very busy year for TMS," observed Wolfgang Schneider, 2012 TMS President, in his welcoming remarks, as he highlighted the new strategic plan guiding TMS's major initiatives. (For details, see the article, "TMS Board of Directors Lead Progress on Strategic Plan" in this issue of JOM.)

A looping PowerPoint show of the TMS annual report was then presented, as attendees enjoyed an opportunity to relax and participate in the many small group dialogs that formed, disassembled, and reassembled during the function.

Robinson said that work is already underway to build on the success of these new approaches to networking for TMS2014 in San Diego. "In general, my takeaway from TMS2013 is that participants felt energized and engaged by these functions," he said. "They also felt appreciated. To me, that makes it all worthwhile."

\section{TMS2013 AWARDS AND RECOGNITION}

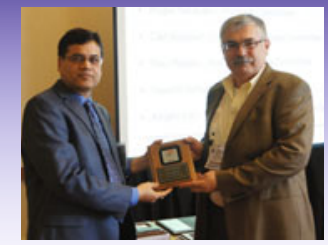

Mishra thanks Raul Rebak (R) for his service as the Nuclear Materials Committee Chair.

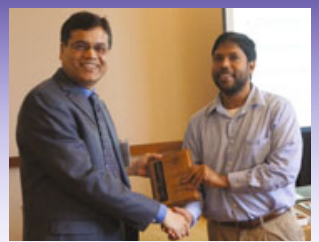

Roger Narayan $(\mathrm{R})$ is recog nized by Mishra for serving as the SMD Programming Repre sentative.

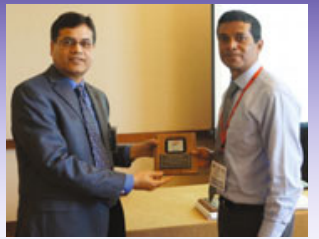

Vasisht Venkatesh $(\mathrm{R})$ is thanked by Mishra for his service as the Titanium Committee Chair.

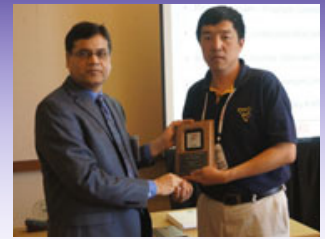

Mishra thanks Xingbo Liu (R) for serving as the High Temperature Alloys Committee Chair. 


\section{THE TMS2013 EXHIBITION: A HUB OF NEW IDEAS}

Many TMS2013 attendees found the expertise they needed to implement the new concepts and approaches that were covered in the symposia sessions during their visits to the TMS2013 Exhibition. The tra- ditional President's Welcoming Reception and a Tuesday Happy Hour kept the exhibit floor lively, while free and discounted lunches offered in the exhibit hall throughout the event made browsing and networking both convenient and productive. TMS welcomed 96 exhibitors, utilizing 11,800 square feet, to TMS2013 and is considering a number of strategies to make the TMS2014 Exhibition in San Diego an even bigger and better event.

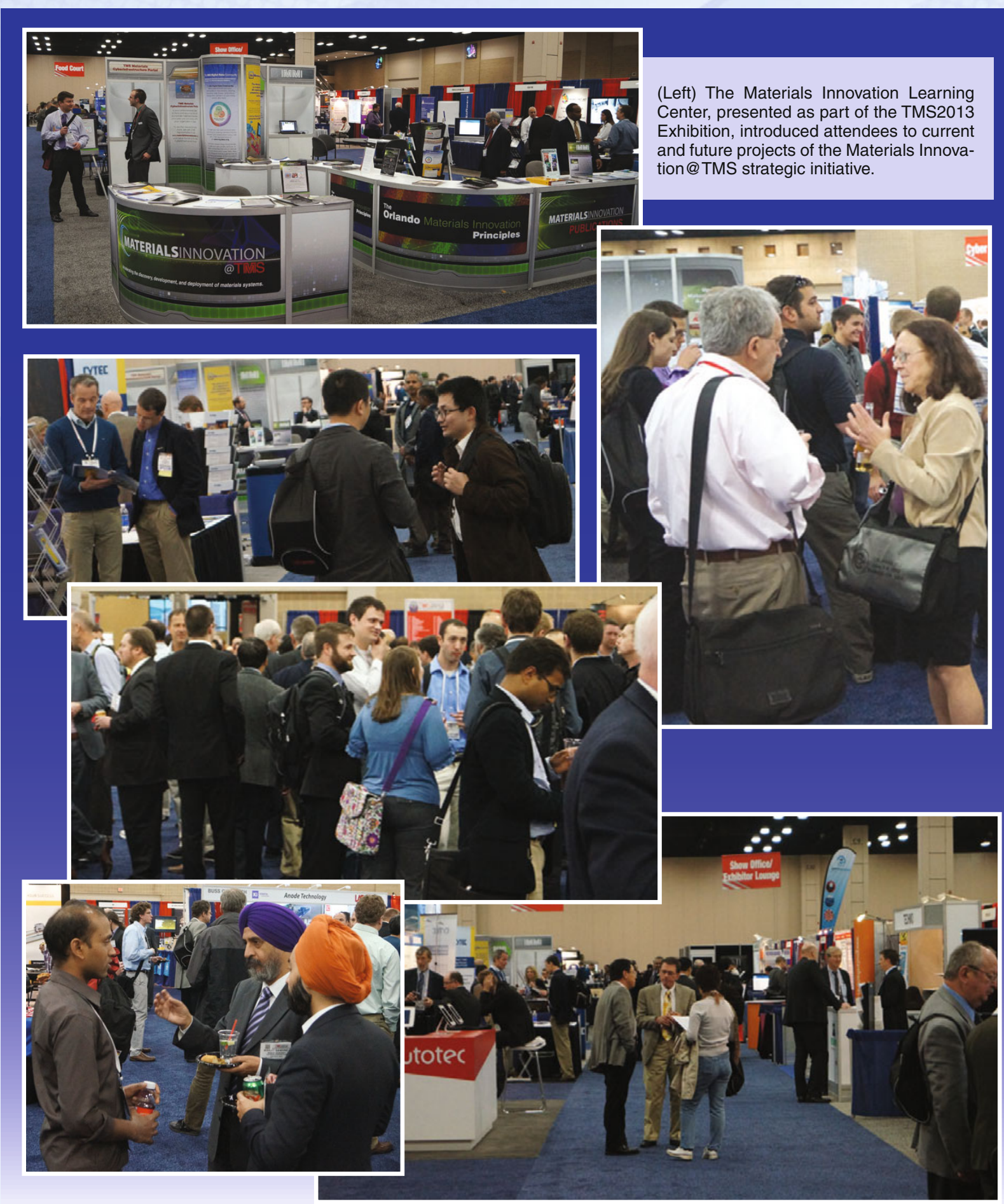




\section{TMS2013 HIGHLIGHTED BY NEW AND ENHANCED YOUNG PROFESSIONAL PROGRAMMING}

\section{Technical Division Poster Contest Debuts}

The TMS Technical Division Young Professional Poster Contest offered early career materials scientists and engineers another opportunity to present their ideas and highlight their work at TMS2013. In addition to valuable professional exposure, each contest winner-one from each TMS technical division-took home a $\$ 500$ prize. Congratulations to the following inaugural poster contest winners:

Electronic, Magnetic \& Photonic Materials Division

Megan Cordill, Erich Schmid Institute, "Fatigue-Induced Grain Coarsening and its Influence on the Electrical Resistance of $\mathrm{Cu}$ Films on Polyimide"

Extraction \& Processing Division Jan de Bakker, BBA, Inc., “A Review of Energy Use in Fine Grinding”

\section{Light Metals Division}

Fadi Abu-Farha, Clemson University, "Friction Stir Back Extrusion (FSBE) of Lightweight Alloys"

Materials Processing \&

Manufacturing Division

Eren Kalay, METU, "Nanocrystal Formation From an Amorphous Precursor"

\section{Structural Materials Division}

Zhenzhen Yu, Oak Ridge National Laboratory, "In-situ Probing of Microscopic Deformation Kinetics in Advanced High-Strength Steels"

\section{Sharing Insights at the Student Career Forum}

Some of TMS's rising leaders played a mentoring role to the next generation of MSE professionals as panelists at the TMS2013 Student Career Forum. The session provided an opportunity for the panel to share viewpoints on a wide range of topics, including differences between academic and industry jobs, determining a career focus after graduation, job search and interview tips, job environment insights, and the value or harm of taking time off after school. The forum ended with a chance for students to have a oneon-one discussion with the panelists.

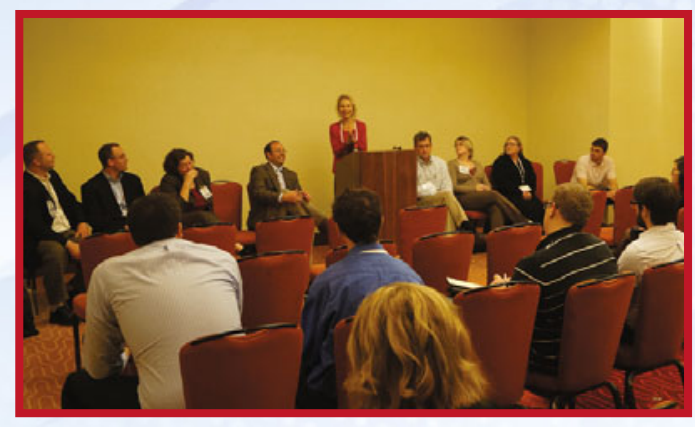

\section{Meet the Candidate Event Forges Professional Connections}

The TMS2013 Meet the Candidate Employment Poster Session expanded on the strength and experience of last year's first-ever event of this type at a TMS Annual Meeting. Even more young researchers presented their professional strengths and career interests to potential employers from universities, companies, and national laboratories. Their featured work comprised a variety of research areas, from traditional metallurgical to biological applications. Research into the characterization, formability, and phase stability of magnesium alloys was particularly well represented.
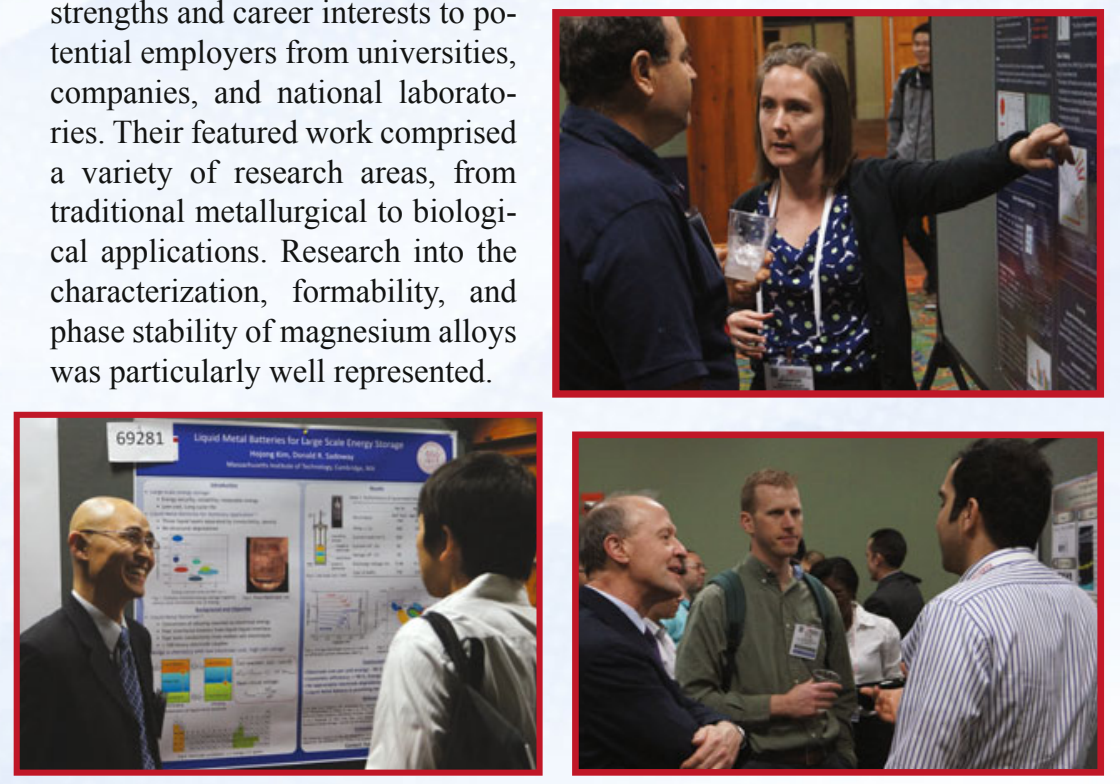

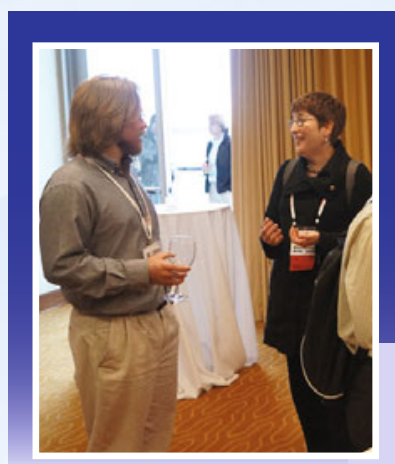

YOUNG PROFESSIONAL HAPPY HOUR RECEPTION
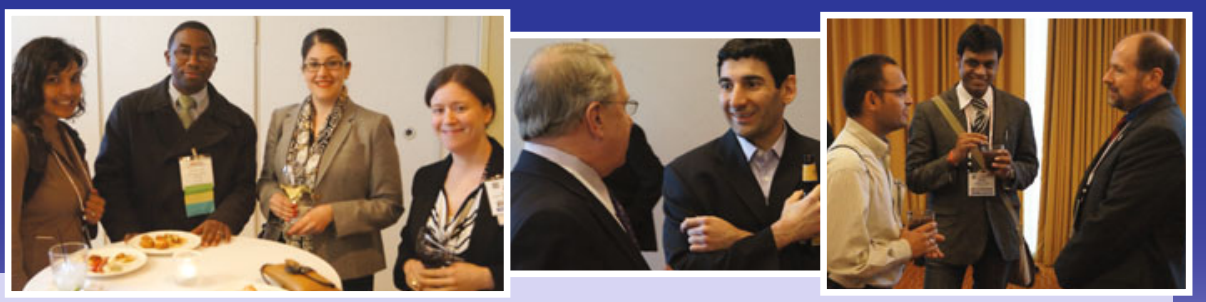

In a new twist on young professional networking events in the past, TMS Board members and other prominent members were invited to attend the TMS2013 Young Professional Happy Hour Reception, as a way to connect seasoned professionals with early career materials scientists and engineers. 


\section{OPENING DOORS AND HAVING FUN AT TMS2013 STUDENT EVENTS Congratulations to the TMS2013 Student Poster Contest Winners}

More than 70 students participated in this year's TMS Technical Division Student Poster Contest, with two winners (one undergraduate and one graduate) selected from each of the five TMS technical divisions to receive a $\$ 500$ prize In addition, two winners (one graduate and one undergraduate) were selected from the Biological Materials Student Poster Contest. From all of these winning entries, two posters were selected to receive an additional \$500 for the Best of Show Award. The TMS2013 Student Poster Contest winners are:

Best of Show

Undergraduate: "Correlation of Pressure to Bonding Capabilities Using Novel Heat Treatment Methods in Prototype Sn-Bi Alloys," W. Tuttle, University of Florida

Graduate: "Direct Titanium Powder Production Through the Use of Pre-Conditioned Magnesium Powder," Amin Oliazadeh, Queen's University

Electronic, Magnetic \& Photonic Materials Division

Undergraduate: "Correlation of Pressure to Bonding Capabilities

Using Novel Heat Treatment Methods in Prototype Sn-Bi Alloys,"

W. Tuttle, University of Florida

Graduate: "Effects on Microstructure and Magnetic Properties of Modified Thermomagnetic Annealing and Heat Treatments on Commercial Alnico Magnet Alloys," Haley Dillon, Ames Laboratory

Extraction \& Processing Division

Undergraduate: "Porosity and Percolation in Sintered Recycled Glass for Polluted Soil Filtering," Gerardo Nazario, University of Puerto Rico at Mayaguez

Graduate: "Direct Titanium Powder Production Through the Use of Pre-Conditioned Magnesium Powder," Amin Oliazadeh, Queen's University

Light Metals Division

Undergraduate: "Effects of Boron and Zinc on Impact Tests of
Al-B-Zn Alloy," Marcos Corchado, University of Puerto RicoMayaguez

Graduate: "Electronic Structure and Properties of Stacking Faults of Mg-X Alloys: A First-Principles Study," William Wang, The Pennsylvania State University

Materials Processing \& Manufacturing Division

Undergraduate: "Dynamic Recrystallization of Stainless Steel 316L: A Comparison of Experimental Results to Computer Simulation," Megan Beck, Boise State University

Graduate: "3D Reconstruction of Prior Beta Grain Orientations in Friction Stir Processed Ti-6Al-4V," Adam Shiveley, United States Air Force

Structural Materials Division

Undergraduate: "Controlled Growth of Ultrathin Molecular Films," Jason Leszczewicz, Western Kentucky University

Graduate: "Effect of Alloying Elements and Spark Plasma Sintering Parameters on Nano-dispersion Formation in Nanostructured Ferritic Steels," Somayeh Pasebani, University of Idaho

Biological Materials Student Poster Contest Graduate: "Bisphosphonate Functionalized Gold Nanoparticles Enabled Enhanced Detection of Breast Micro Calcification," Lisa Cole, University of Notre Dame

Undergraduate: "Effect of Surface Treatments on Titanium Alloys," Maria Hernandez, University of Texas Pan American

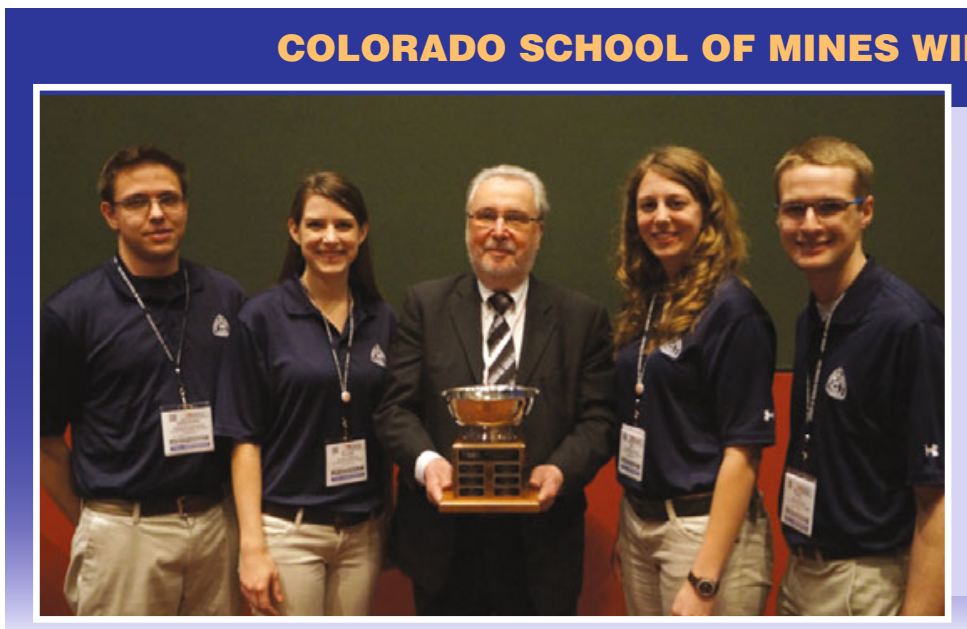

Colorado School of Mines took home the Materials Bowl Trophy for the second year in a row, beating The University of British Columbia in a hotly contested championship round. Pictured are members of the winning team as they are officially awarded their trophy (L-R): Greg Lehnhoff (captain), Ellen Verkler, 2012 TMS President Wolfgang Schneider, Saundra Hunter, and Paul Wilson. Also competing in the TMS2013 Materials Bowl was the University of Utah, Arizona State University, Missouri University of Science \& Technology, University of Illinois (Urbana-Champaign), University of Alabama (Birmingham), Florida International University, The Ohio State University, University of Central Florida, Indian Institute of Technology (Madras), and University of Puerto Rico (Mayaguez).

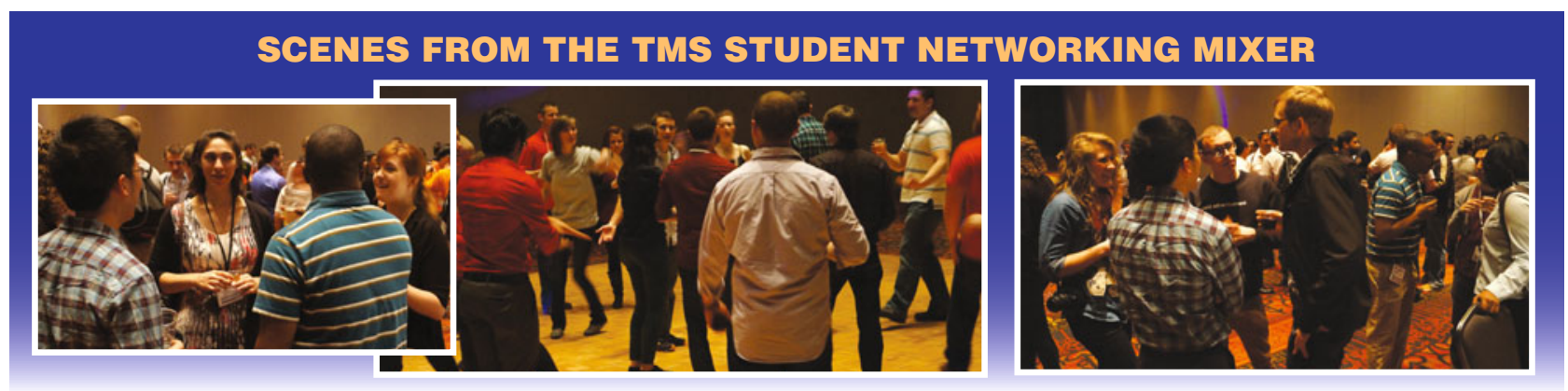




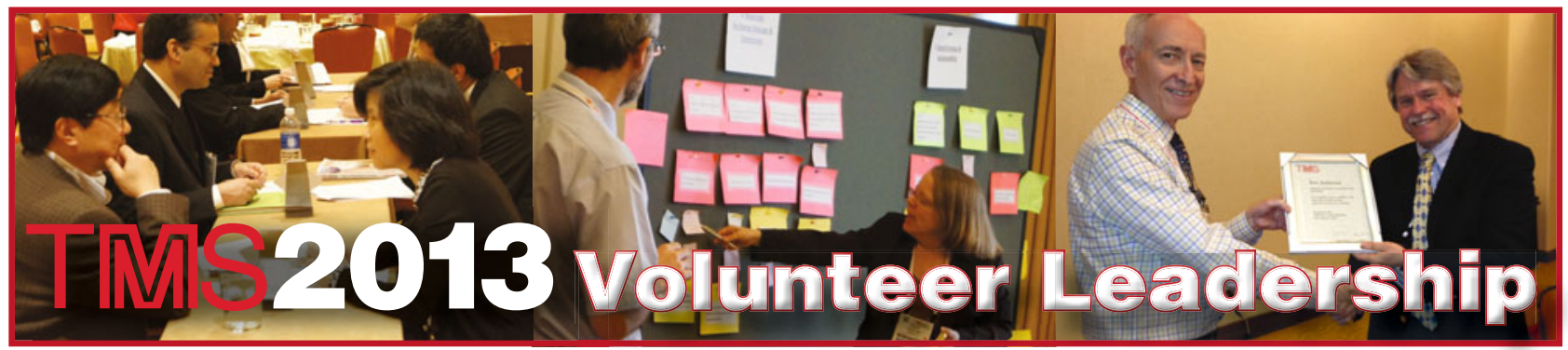

While certainly the centerpiece, the technical sessions offered at TMS2013 really only tell part of the story of any TMS Annual Meeting experience. For a small army of TMS volunteers, that journey actually begins months before as they engage in organizing sessions, judging awards, and coordinating events. The work continues during the Annual Meeting itself -81

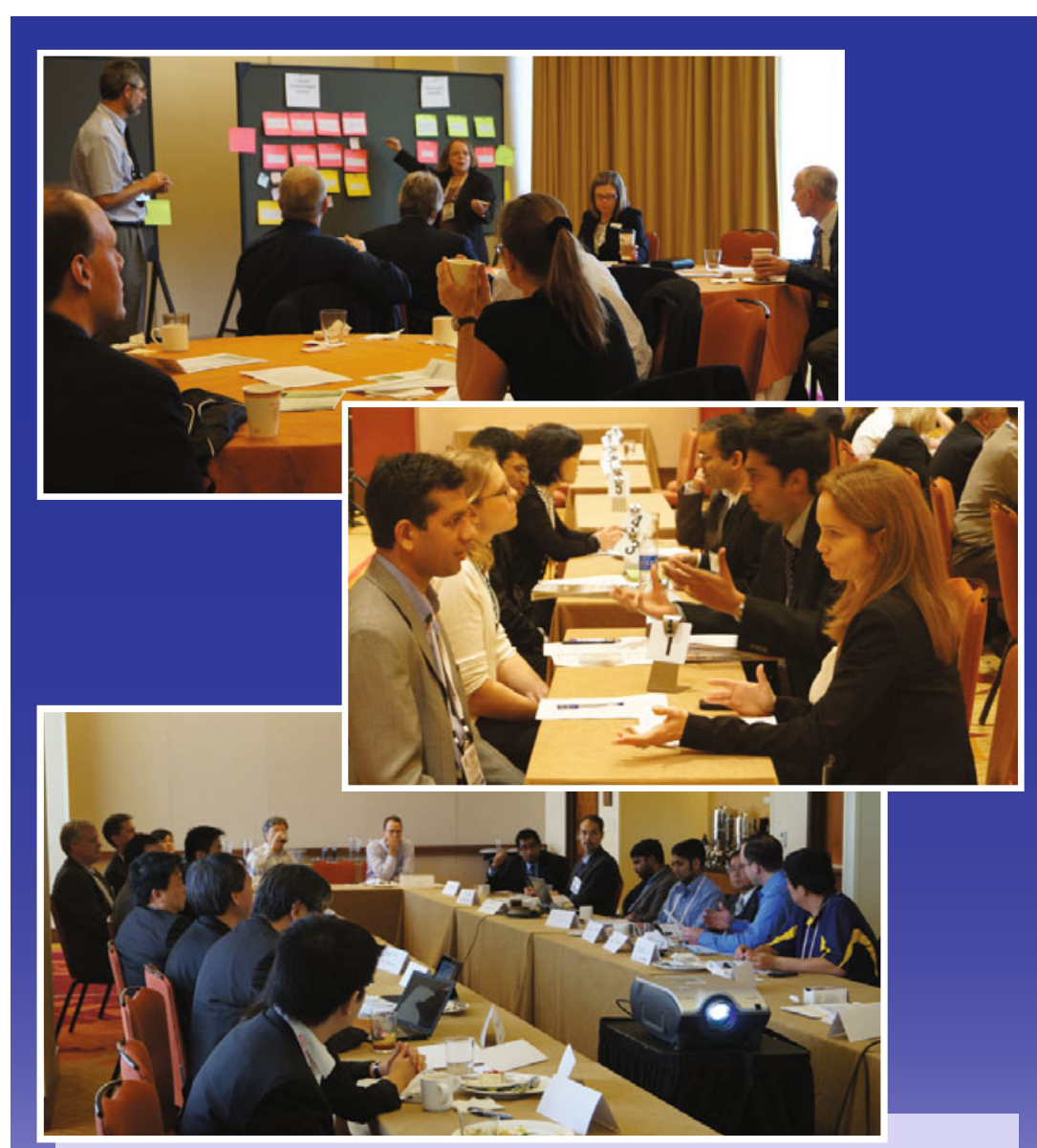

(Top) Cindy Belt, Past Energy Committee Chair, facilitated a session of representatives from more than ten TMS energy-related committees to identify opportunities for collaboration on programming and activities. (Center) A speed-networking program offered as the TMS2013 Peer-to-Peer Networking Event enabled participants to make connections with ten different colleagues, in one-on-one sessions lasting less than ten minutes at a time. (Bottom) The EMPMD Council meeting was one of 81 scheduled volunteer working sessions that took place during TMS2013. committee and working group meetings were scheduled during TMS2013, with countless other informal sessions taking place in hallways, lounges, and restaurants.

Helping to shape a successful conference is rewarding in itself, but many individuals are also quick to cite a number of additional benefits gained through interacting with other volun-

teers. "TMS depends on volunteers to successfully serve the field of materials science. However, I have found that volunteering has provided me with the ability to grow my leadership skills, learn how to successfully communicate, meet new colleagues and learn about emerging materials developments," said Molly Kennedy, Assistant Professor, Clemson University.

Carl Boehlert, Associate Professor, Michigan State University, also observed that volunteering with TMS can have an impact far beyond the walls of a convention center. "My first volunteer role with TMS was probably when I volunteered to be a student monitor during a technical session," he said. "For me, probably the greatest aspect of volunteering for TMS over the years is the satisfaction that I am doing something that helps the greater good of the society."

Recognizing the tremendous value of its volunteers to its own activities and the MSE community at large, TMS has made "enhancing its status as a volunteer-centric society" one of the top priorities in its strategic plan. An outgrowth of this has been the launch of several new volunteer benefits at the Annual Meeting.

The very popular Volunteer Leadership Lounge, first established at TMS2012, gave individuals involved in the programming and coordination aspects of the conference a chance to grab a snack, charge phones and check e-mails, and meet with other volunteers. A Peer-to-Peer Networking Event offered at TMS2013 to TMS committee, division, and board members, as well as symposium organizers and Young Leader Award winners, introduced attendees to a new approach in making professional connections. And a Global Networking Lounge, opened for the first time at TMS2013, provided 
interpretation and translation support to international attendees.

Additional resources are currently under development to support and thank the TMS volunteers who make the Annual Meeting and so many other TMS products, services, and activities possible. As appreciated as these new and evolving volunteer benefits might be, C. Robert Kao, Professor, National Taiwan University, notes that these are just enhancements to an already very strong value proposition. "Everyone who regularly attends TMS meetings should participate in technical committees of his/her interests. If not, he or she is not getting the full worth of the time and expense spent in attending these conferences," he said. "For me, volunteer activities are the most rewarding experience of my professional career."

\section{IN THEIR OWN WORDS: THE 2013 TMS FELLOWS}

The class of Fellow is the highest honor bestowed by TMS, recognizing not only seminal contributions to the MSE body of knowledge, but also the lasting impact on the profession through outstanding service as a TMS volunteer. This year, four new Fellows were inducted into this elite group at the TMS-AIME Awards program-David J. Srolovitz, Joseph Bordogna Professor of Engineering and Applied Science, University of Pennsylvania; Robert D. Shull, NIST Fellow, National Institute of Standards and Technology (NIST), and 2007 TMS President; George T. (Rusty) Gray III, Fellow, Los Alamos National Laboratory, and 2010 TMS President; and Peter Voorhees, Professor, Northwestern University. Each offered brief reflections during the ceremony on the significance of the Fellow award, while also highlighting the importance of friends, colleagues, and TMS involvement in their professional journeys. Several of these are presented below, and all that were shared had the effect, as Voorhees observed, of making the program "a memorable occasion."

\section{"I am proud to be named a TMS Fellow.}

A TMS meeting was the first conference I ever attended as a $\mathrm{Ph} . \mathrm{D}$. student and I have been a regular participant ever since. I feel as if TMS is my scientific home. I am proud to accept this award in the presence of my Ph.D. advisors, Professors Vaclav Vitek and Takeshi Egami, both of whom taught me how to be a scientist. I am proud to accept this award in the presence of many of my students, including incoming TMS President Liz HolmI have learned more from my students than my advisors. I am proud to accept this award in the presence of several collaborators-many of whom are TMS Fellows-from whom I have learned to be part of a scientific community and all of whom have become dear friends. I have had the privilege of working in universities, in national laboratories, and in industry, as well as in institutions in several countries. (True, I have a short attention span.) Doing science with colleagues from all of these has made science what it is to me-it is as fundamental as breathing. Thank you for this honor!"

\section{—David Srolovitz}

\section{"This is awesome!}

"I cannot think of any other award I've received that means more to me! I feel humbled when I realize the high caliber of "this select group" of TMS Fellows I am now joining! And, it is particularly nice to be doing it with my good friends of many years:
Dave, Rusty, and Peter. I'm sure TMS has now recognized its mistake in selecting me. But it is now too late. I am NOT giving it back!

"I'd like to thank you, my colleagues, for giving me such good ideas, and being such good and exacting critics so my science was the best it could be. And, I'd like to thank my wife, Mary, for putting up with all those nights when I'd come home late for dinner because I had lost track of time or because that experiment I was conducting didn't have the decency to finish on time! And lastly, I'd like to thank TMS for honoring me with this award. Thank you all."-Robert D. Shull

\section{"I am, like the materials I study, a product of a raw material plus path-dependent processing.}

I am indebted to my parents, my family, and all the professors and mentors who have shaped the scientist that I am today. I am indebted to the South Dakota School of Mines, Carnegie Mellon University, and the Technical University Hamburg-Harburg for my education and training. I have been blessed over my career with an amazing group of colleagues, co-workers, and post-docs - especially post-docs - I think I learned far more from many of them, than they did from me. Finally, I have been blessed and honored for the past 28 years at Los Alamos National Laboratory to have been able to work with an amazing group of colleagues, and been supported by great management and an amazing staff without which I would not have achieved this award. Thank you!"-Rusty Gray

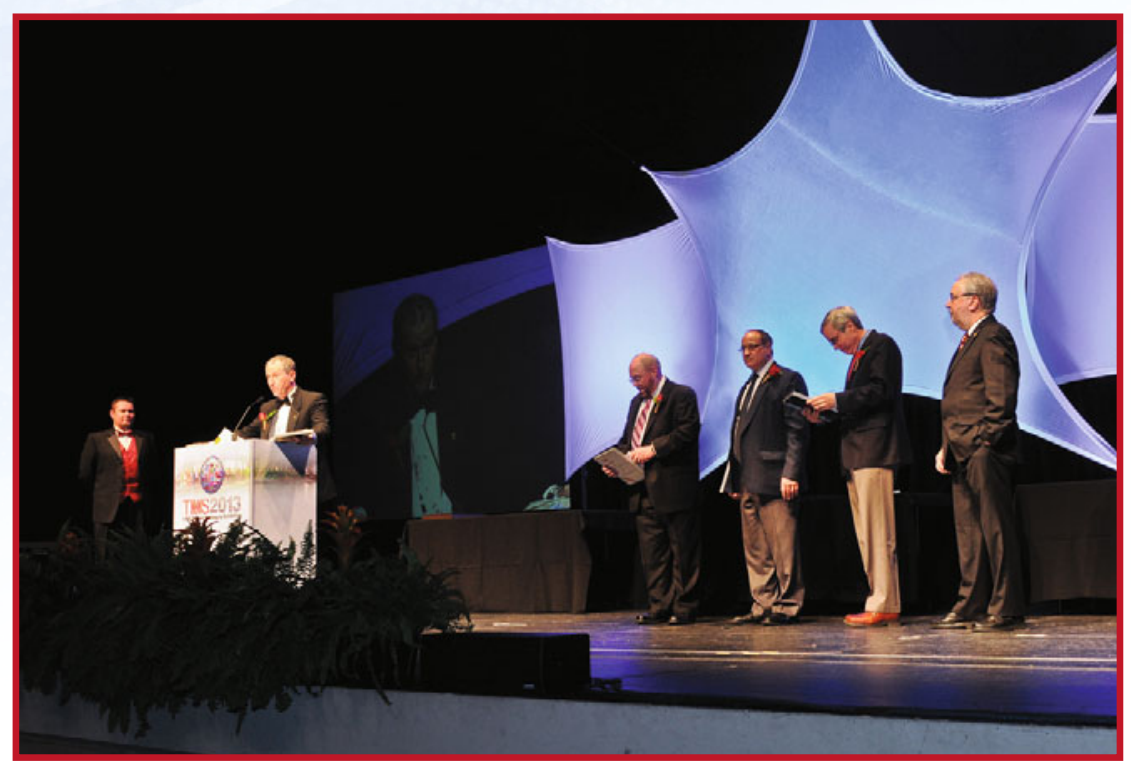

Rusty Gray (podium) offers his remarks at the TMS-AIME Award program. Waiting their turns to speak are (L-R): Robert Shull, David J. Srolovitz, and Peter Voorhees. 2012 TMS President Wolfgang Schneider (far right) presented them with their awards. 


\section{COMMITTEE CHARTS FUTURE FOR THE

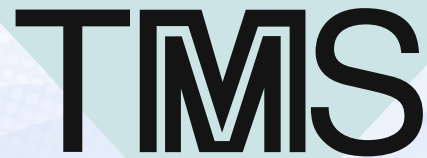

F O U N D A T I O N

Ensuring the future vitality of MSE

by investing in its youngest professionals and emerging leaders has been a special focus of the TMS Foundation since its inception in 1993. Much of this work has centered on supporting student scholarships, as well as awards to recognize and build on the accomplishments of early career scientists and engineers.

This track record has positioned the Foundation to play a key role in advancing the strategic goals adopted by the TMS Board of Directors in 2012, most notably the intended target to "be the destination society for young professionals: technically, professionally and socially." Laying the groundwork for this next phase of service to the MSE community is the TMS Foundation Board Revitalization Committee, appointed by the TMS Foundation Board of Trustees and chaired by Robert Wagoner, Professor Emeritus, The Ohio State University, and the 1997 TMS President.

"I think most people know the importance of charitable organizations, and in particular foundations of materials societies," said Wagoner. "And, most know the unique perspective that TMS brings in terms of being the professional materials society. A stronger TMS Foundation will bring together those two aspects to better serve MSE professionals, particularly those in the early stages of their careers."

Informing the work of the Revitalization Committee is a comprehensive survey conducted in late 2012 that examined aware-

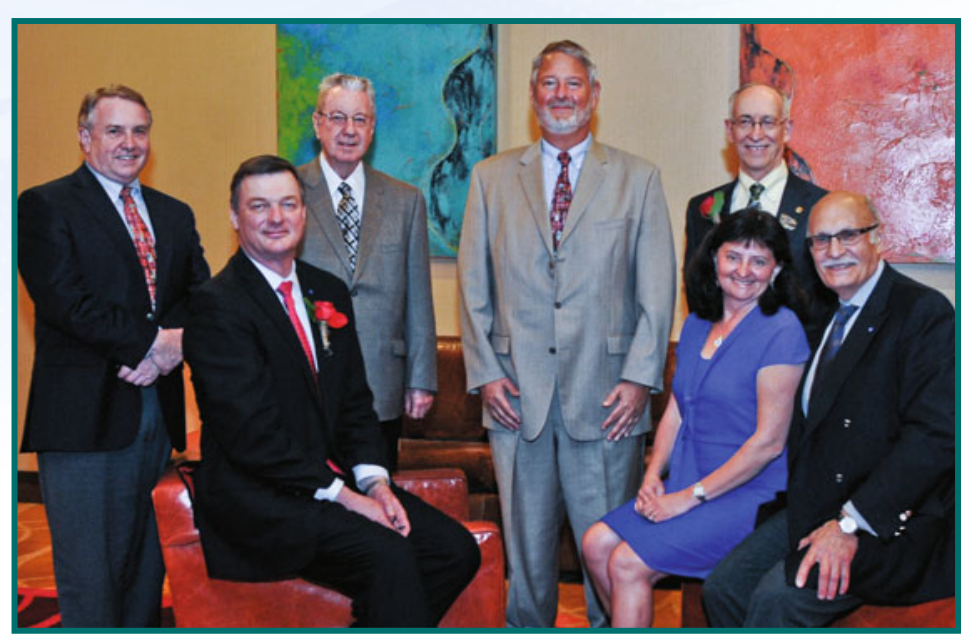

The TMS Foundation Board Revitalization Committee $(L-R)$ : Wayne Jones, professor, University of Michigan and 1999 TMS president; Jeff Wadsworth, president and CEO, Battelle; Alexander Scott, Retired TMS executive director; Rob Wagoner, Professor Emeritus, The Ohio State University; Tresa Pollock, 2005 TMS president, and Alcoa Professor of Materials and Materials Department Chair, University of California, Santa Barbara; Garry Warren, professor, University of Alabama and 2011 TMS president; Diran Apelian, 2008 TMS president, and Alcoa-Howmet Professor of Mechanical Engineering and Director, Metal Processing Institute, Worcester Polytechnic Institute. Not pictured: Alton Romig, Vice President and General Manager, Advanced Development Programs, Lockheed Martin Aeronautics; Paul Campbell, 1995 TMS president, and current South Carolina state senator. ness, perceptions, and support of the Foundation by TMS members. "The most important thing we discovered from surveys was a sort of paradox," said Wagoner. "Most TMS members little about it. They are willing to support the Foundation and its ctivities, but have not really been asked to do so.'

To more clearly define the case for support, the TMS Founon of TMS members in the early years of their careers during TMS2013. While the insights from this event are still being tiative "TMS has been very supportive of young professionals for years, through the Young Leader Professional Development Award and the establishment of international partnerships focused on young TMS members. These are unique programs that many other professional societies do not offer," he said. "As rt of a volunteer-driven professional society, the TMS Founls is vital to the future growth of the society and profession. The Foundation's focus on programs for young professionals is important to the continued growth and development of this pipeline."

In coming months, the TMS Foundation Board of Trustees will review the results of the survey and focus group as it considers a Foundation infrastructure and development plan that will support broader engagement in advancing TMS's strategic goals. Their final recommendations are slated to be presented to the TMS Board of Directors in late June. "A revitalized TMS Foundation will make possible the operation of sustainable programs to benefit TMS professional members and students," said Wagoner. "The exact nature of the programs will be decided based on proposals, interest, and feasibility. The committee was asked to look at each of these aspects and propose a plan to move forward in an ambitious, but sustainable way."

The committee roster includes some of the most active, long-established leaders in the material profession (see accompanying photograph). Wagoner notes that this distinguished group is enthusiastic about the potential impact of a revitalized TMS Foundation and believes that the Foundation's renewed focus and mission will resonate equally with the greater TMS membership. "I have benefitted greatly from being involved with TMS and the materials community and am now in a position to pay back by volunteering time and resources," he said. "It is an honor to do so." 